\title{
Intelligent Computing with Levenberg-Marquardt Backpropagation Neural Networks for Third-Grade Nanofluid Over a Stretched Sheet with Convective Conditions
}

\author{
Muhammad Shoaib ${ }^{1}$. Muhammad Asif Zahoor Raja ${ }^{2}$. Ghania Zubair ${ }^{1}$. Imrana Farhat ${ }^{1}$. \\ Kottakkaran Sooppy Nisar $^{3}$ (D) Zulqurnain Sabir ${ }^{4} \cdot$ Wasim Jamshed $^{5}$
}

Received: 7 April 2021 / Accepted: 9 September 2021 / Published online: 29 September 2021

(c) King Fahd University of Petroleum \& Minerals 2021

\begin{abstract}
This article discussed the influence of activation energy on MHD flow of third-grade nanofluid model (MHD-TGNFM) along with the convective conditions and used the technique of backpropagation in artificial neural network using Levenberg-Marquardt technique (BANN-LMT). The PDEs representing (MHD-TGNFM) transformed into the system of ODEs. The dataset for BANN-LMT is computed for the six scenarios by using the Adam numerical method by varying the local Hartman number $(\mathrm{Ha})$, Prandtl number $(\mathrm{Pr})$, local chemical reaction parameter $(\sigma)$, Schmidt number $(\mathrm{Sc})$, concentration Biot number $\left(\gamma_{2}\right)$ and thermal Biot number $\left(\gamma_{1}\right)$. By testing, validation and training process of (BANN-LMT), the estimated solutions are interpreted for (MHD-TGNFM). The validation of the performance of (BANN-LMT) is done through the MSE, error histogram and regression analysis. The concentration profile increases when there is an increase in Biot number and the local Hartmann number; meanwhile, it decreases for the higher values of Schmidt number and the local chemical reaction parameter.
\end{abstract}

Keywords MHD flow $\cdot$ Activation energy $\cdot$ Levenberg-Marquardt technique $\cdot$ Nanofluid $\cdot$ Artificial neural networks

\section{Abbreviations}

Muhammad Asif Zahoor Raja

rajamaz@yuntech.edu.tw

$凶$ Kottakkaran Sooppy Nisar

ksnisar1@gmail.com; n.sooppy@psau.edu.sa

Muhammad Shoaib

dr.shoaib@cuiatk.edu.pk

Ghania Zubair

sp20-rmt-002@ cuiatk.edu.pk

Imrana Farhat

imranafarhat4@gail.com

Zulqurnain Sabir

zulqurnain_maths@hu.edu.pk

Wasim Jamshed

wasiktk@hotmail.com

1 Department of Mathematics, COMSATS University Islamabad, Attock Campus, Attock, Pakistan

2 Future Technology Research Center, National Yunlin University of Science and Technology, 123 University Road, Section 3, Douliou, Yunlin 64002, Taiwan, People's Republic of China

$\begin{array}{ll}\text { MHD } & \text { Magnetohydrodynamic } \\ \sigma & \text { Local chemical reaction parameter } \\ \operatorname{Pr} & \text { Prandtl number } \\ \gamma_{2} & \text { Concentration Biot number } \\ \epsilon_{1} & \text { Material parameter } \\ \epsilon_{3} & \text { Material parameter } \\ \mathrm{Nt} & \text { Thermophoresis parameter } \\ \zeta & \text { Material parameter } \\ E & \text { Activation energy } \\ \text { BANN-LMT } & \text { Backpropagation in artificial neural net- } \\ & \text { work using Levenberg-Marquardt tech- } \\ & \text { nique } \\ p & \text { Pressure } \\ 3 & \text { Department of Mathematics, College of Arts and Science, } \\ & \text { Prince Sattam Bin Abdulaziz University, Wadi Aldawaser } \\ \text { 11991, Saudi Arabia } & \\ 4 & \text { Department of Mathematics and Statistics, Hazara } \\ \text { University, Mansehra, Pakistan } & \\ \text { Department of Mathematics, Capital University of Science } \\ \text { and Technology (CUST), Islamabad 44000, Pakistan }\end{array}$




$\begin{array}{ll}\tilde{\mu} & \text { Dynamic viscosity } \\ \widetilde{V} & \text { Fluid velocity } \\ \mathrm{J} / \mathrm{mol} & \left.\text { Joule per mole (unit of } E_{a}\right) \\ v & \text { Kinematic viscosity } \\ \rho \mathrm{f} & \text { Density of fluid } \\ T & \text { Temperature } \\ \sigma^{*} & \text { Electric conductivity } \\ k & \text { Thermal conductivity } \\ \alpha & \text { Thermal diffusivity } \\ (\rho C)_{f} & \text { Heat capacity } \\ D_{\mathrm{T}} & \text { Thermophoresis coefficient } \\ C & \text { Concentration } \\ T_{\infty} & \text { Temperature far away from sheet } \\ \mathrm{MSE} & \text { Mean square error } \\ \mathrm{Ha} & \text { Local Hartman number } \\ \gamma_{1} & \text { Thermal Biot number } \\ \mathrm{Sc} & \text { Schmidt number } \\ \epsilon_{2} & \text { Material parameter } \\ \mathrm{Nb} & \text { Brownian movement parameter } \\ \delta & \text { Temperature difference parameter } \\ n & \text { Fitted rate constant } \\ \mathrm{Re} & \text { Reynolds number } \\ \mathrm{MHD}-\mathrm{TGNFM} & \text { Magnetohydrodynamic flow of third-grade } \\ \mathrm{Pa} & \text { nanofluid model } \\ \mathrm{Pa} \mathrm{s} & \text { Pascal (unit of pressure) } \\ E_{\mathrm{a}} & \text { Pascal second (unit of dynamic viscosity) } \\ K_{r} & \text { Activation energy } \\ \mathrm{St} & \text { Reaction rate } \\ \mathrm{Kg} / \mathrm{m}^{3} & \text { Stokes (unit of } v \text { ) } \\ \mathrm{K} & \text { Unity of density } \\ \mathrm{S} / \mathrm{m} & \text { Kelvin } \\ \mathrm{W} / \mathrm{m}-\mathrm{K} & \text { Siemens per meter (unit of } \sigma^{*} \text { ) } \\ \mathrm{m}^{2} / \mathrm{s} & \text { Watt per meter-Kelvin (unit of k) } \\ \mathrm{J} / \mathrm{K} & \text { Square meter per second (unit of } \alpha \text { ) } \\ D_{\mathrm{B}} & \text { Joule per kelvin (unit of }(\rho C)_{f} \text { ) } \\ \mathrm{M} & \text { Brownian diffusion coefficient } \\ C_{\infty} & \text { Molarity (unit of C) } \\ & \text { Ambient temperature } \\ & \end{array}$

\section{Introduction}

The liquid that carries the nanometer-sized solid particle dispersion is called nanofluid. There are two main categories: first one is single-phase modeling and second is two-phase modeling. In the single-phase modeling, both the nanoparticles and the liquid examine as a monophasic mixture, whereas in the two-phase modeling nanoparticles are considered explicitly from the base liquid and its properties.

Choi and Eastman [1] concluded that the cooling potential of typical liquids can be improved by the inclusion of nanoparticles into basic liquids. There are some applications in which nanofluids are very useful like grinding machine and air-conditioners. The random movement of small particles in a fluid is called Brownian motion (BM). The importance of BM in enhanced thermal conductivity of nanofluids was addressed by Jang and Choi [2]. Shukla and Dhir [3] investigated the influence of BM on the nanofluid's thermal efficiency.

Viscosity of nanofluids was experimentally reviewed by Bashirnezhad [4]. The transport properties of nanoliquids were discussed by Michaelides [5]. Slip flow over a nanofluids and the radiative heat transmission were examined by Souayeh et al. [6]. With thermal radiation, the magnetic flow of viscous liquid was analyzed by Makinde et al. [7]. Sheremet et al. [8] examined the magnetic flow of nanoliquid (unsteady) in a cavity. Makinde and Aziz [9] concluded that the concentration of nanoparticles upgrades for the greater Biot number.

Buongiorno [10] studied the Brownian diffusion and convective transport of nanofluids. The flow of nanofluids via nanochannel was addressed by Ghahremanian et al. [11]. Magnetohydrodynamic (MHD) studies represent the motion of electroconductive fluid in a magnetic field. Magnetohydrodynamic flow of nanofluids (non-Newtonian) along with the activation energy was studied by Ahmad et al. [12].

Through a stretched surface, the thermodiffusion effects on nanofluids (magnetic) were addressed by Awad et al. [13]. The fluid's viscosity takes energy by the movement of the liquid and changes it in the internal energy. This procedure is irreversible (partially) and known as viscous dissipation. The impact of viscous dissipation through a stretched surface on unsteady magnetohydrodynamic flow was studied by Reddy et al. [14]. He also addressed the impact of heat source over a stretching sheet on magnetohydrodynamic flow (unsteady). Through a porous stretched sheet, Tak and Lodha [15] studied the impact of viscous dissipation and transverse magnetic field on flow. Zami et al. [16] demonstrated the heat transfer and the boundary layer flow of a nanoliquid through a nonlinearly porous stretchable/non-stretchable sheet.

Ramzan et al. [17] incorporated the impact of bioconvection on three-dimensional tangential hyperbolic partially ionized nanofluid system. Mahanthesh [18] demonstrated the significance of viscous and Joule heating effects on heat transport of hybrid nanoliquid. The BrinkmanForchheimer flow of single-walled and multi-walled carbon nanotube fluid in a microchannel was investigated by Shashikumar [19]. Under uniform mass and heat flux conditions, the statistical and exact computations of radiated flow of Casson and nanofluid were studied by Mackolil [20]. With thermophoresis and BM effects, the dynamics of thirdgrade non-Newtonian liquid were analyzed by Mahanthesh [21]. Mackoli1 [22] carried out a sensitivity analysis of MHD Marangoni convection of nanofluid. 
Mahanthesh [23] studied the influence of thermal radiation on the steady 3D flow of nanoliquid over a stretched surface. Impacts of aluminum nanoparticles are observed through experimental study by Lade et al. [24]. The 2-phase MHD flow of a fluid through a dust suspension was demonstrated by Mahanthesh [25]. The exact and statistical investigation of magnetohydrodynamic flow due to hybrid nanosized particles dispersed in hybrid base liquid was carried out by Mahanthesh [26]. In magnetic field along with boundary conditions, the heat transfer features of nanofluid through a rotating plate were discussed by Mahanthesh [27]. The hybrid nanofluid flow in an annulus with quadratic thermal radiation was examined by Thriveni [28].

In a non-Darcian permeable surface, the unsteady magnetohydrodynamic flow of a nanofluid was demonstrated by Rahman and Gamal [29]. With Newtonian heating, the unsteady MHD flow in a permeable medium was studied by Hussanan et al. [30]. Reactants need an amount of energy to activate a chemical reaction which is known as activation energy. Effect of binary chemical reaction and activation energy in MHD flow over a vertical sheet for a nanofluid was demonstrated by Mustafa et al. [31].

Khanafer and Vafai studied the dynamic viscosity and the thermal conductivity effects in the presence of convective heat transfer [32]. In a permeable medium, the laminar flow of viscous fluid with nanoparticles was examined by Hamad et al. [33]. The flow of nanofluid effected by the viscous heating and convection was analyzed by Pal and Mandal [34].

Exponentially stretched sheet and the rotating flow of nanofluid were numerically analyzed by Mushtaq et al. [35]. Magyari and Keller [36] examined the heat transfer properties. Cortell [37] analyzed the thermal boundary layer. Over a stretching surface, the MHD flow of nanofluid with Navier slip conditions was studied by Seth and Meshra [38].

W Jamshed utilized the Maxwell nanoliquid in his research problem based on thermal examination in solar collector [39]. Al Hossainy [40] discussed in his paper the heat transport phenomenon of magnetohydrodynamic radiative Carreau hybrid nanoliquid. Jamshed [41] discussed a solar thermal application by utilizing hybrid nanoliquid in his research model. Over a porous stretched surface, the flow of incompressible micropolar Prandtl liquid was investigated by Sajid [42]. He [43] also studied the heat transfer characteristics of Reiner-Philippoff hybrid nanoliquid in solar aircraft wings. The analysis of heat transfer of magnetohydrodynamic rotating flow of nanofluid over a stretched sheet was carried out by Shahzad [44]. Over an inclined plate, the flow of third-grade nanoliquid along with the lubrication impacts was discussed by Nazeer [45]. With the Joule heating impacts, the flow of nth-order reactive fluid over an elongated surface was examined by Shamshuddin [46].

This model involves the third-grade nanofluid, and there are many research articles that involve the applications of third-grade nanofluid. Sajid [47] examined the third-grade nanofluid flow over an infinite permeable sheet. Similarly, the same problem of the flow of third-grade nanofluid past an infinite porous sheet is studied by Rajagopal et al. [48]. Cortell [49] computed the mathematical solution for this problem by applying the Runge-Kutta method. Mekheimer [50] used third-grade nanofluid in his research as an application of cancer therapy. Hatami et al. [51] and Hamzehnezhad et al. [52] also used third-grade non-Newtonian fluid in their research problem.

In the presented research article, the authors have considered the backpropagation in artificial neural network (ANN) using Levenberg-Marquardt technique (BANN-LMT) has been developed to analyze the MHD flow of third-grade nanofluid model (MHD-TGNFM) along with the convective conditions. Xu [53] applied artificial neural networks to solve the issues related to solid waste. S Mangini [54] studied the quantum computing models for the ANNs and there are many other research articles based on the applications of ANN [55-58].

There are different numerical methods to investigate the flow of third-grade nanofluid over a stretched sheet, but the stochastic numerical method is used for the flow problem due to their effectiveness and worth. Recently, many researchers implemented the stochastic numerical technique for fluid flow systems [59-61]. Some artificial intelligence-based techniques are used by the research workers [62-65]. MAT$\mathrm{LAB}$ and Mathematica infrastructures are utilized for these numerical computations. The solution of the mathematical expression for MHD-TGNFM is calculated viably by using the technique of backpropagation in artificial neural network using the Levenberg-Marquardt technique (BANN-LMT). The value and worth of the suggested BANN-LMT were established by comparing the results of the proposed BANNLMT to the results of Adams numerical technique for various scenarios of MHD-TGNFM mathematical model. Multiple implementations of BANN-LMT in terms of MSE-based indices have demonstrated the performance's authenticity and verification through statistical analyses. Aside from the MHD-TGNFM mathematical model's accurate and precise results, the ease of comprehending the ideas, consistency, smooth operation and extendibility is also noteworthy advantages.

In the presented study, a novel application of the integrated stochastic computational intelligent solver BANN-LMT is presented with the following salient features:

- The solution of the mathematical expression for MHDTGNFM is calculated viably by using the technique of backpropagation in artificial neural network using the Levenberg-Marquardt technique (BANN-LMT).

- The worth and the value of the suggested BANN-LMT were established by comparing the results of BANN-LMT 
to the results of Adams methods for various scenarios of MHD-TGNFM mathematical model.

- Multiple implementations of BANN-LMT in terms of MSE-based indices have proven the verification and authenticity of the performance through statistical assessment investigations.

- Beside the accurate and precise results for the MHDTGNFM and easy to understand the concepts, smooth operation, exhaustive applicability, consistency and extendibility are another valuable perks.

\section{Mathematical Modeling}

This paper discusses the 2D (MHD-TGNFM) along with the convective mass and heat conditions. Due to a stretched sheet, the flow is generated. The exertion of magnetic field $\left(B_{0}\right)$ to the surface is in the perpendicular direction. The fluid phases and the nanoparticles are supposed to be in the thermal equilibrium state. Taking the small value of Reynolds number (magnetic) can ignore the impact of electric field and Hall current. Here, the model is examined in Cartesian coordinate system in which $y$-axis is in the perpendicular direction to the sheet and the stretched sheet is along the $x$-axis. The sheet is stretched at the $x$-axis where $y=0$. And the velocity is $u_{\mathrm{w}}(x)$ $=a x^{\mathrm{m}}$, where $\mathrm{m}$ and a are assumed as constants. By using the heat convection, the temperature at the sheet was controlled. $h 1$ and $h 2$ are the heat and mass transfer coefficients. Bruce [66] and Joseph [67] experimentally showed that there are materials that are

a. Weekly shear thinning but exhibit strong normal stresses. (first order)

b. Equal shear thinning and normal stress effects. (second order)

c. Strongly shear thinning but exhibit weak normal stresses. (third order)

In this study, third-grade fluid is examined. The main aim of this investigation is to give the numerical solution of MHDTGNFM. There are some equations that govern the flow in (MHD-TGNFM). For third-order fluid, the Cauchy stressed tensor is:

$$
\begin{aligned}
\tau^{*}= & p I+\tilde{\mu} \hat{A}_{1}^{*}+\alpha_{1} \hat{A}_{2}^{*}+\alpha_{2} \hat{A}_{2}^{* 2}+\beta_{1} \hat{A}_{3}^{*} \\
& +\beta_{2}\left(\hat{A}_{2}^{*} \hat{A}_{1}^{*}+\hat{A}_{1}^{*} \hat{A}_{2}^{*}\right)+\beta_{3}\left(\operatorname{Tr} \hat{A}_{1}^{* 2}\right) \hat{A}_{1}^{*}
\end{aligned}
$$

where $\tilde{\mu}$ is the dynamic velocity, $\mathrm{p}$ is the pressure, $\alpha_{1}, \alpha_{2}, \beta_{1}, \beta_{2}$ and $\beta_{3}$ are the material constants. Now the Rivlin-Ericksen tensor $\left(\hat{A}_{1}^{*}, \hat{A}_{j}^{*}\right)$ is:

$\hat{A}_{1}^{*}=\nabla \breve{V}+(\nabla \breve{V})^{\overline{\mathrm{T}}}$
$\hat{A}_{j}^{*}=\frac{\mathrm{d} \hat{A}_{j-1}^{*}}{\mathrm{~d} t}+\hat{A}_{j-1}^{*} L+L^{\overline{\mathrm{T}}} \hat{A}_{j-1}^{*},(j>1)$,

where $\frac{\mathrm{d}}{\mathrm{d} t}=$ material derivative, $\breve{V}=$ velocity of fluid.

The constraints drive from Clausius-Duhem inequality are the following:

$\tilde{\mu} \geq 0,\left|\alpha_{1}+\alpha_{2}\right| \leq \sqrt{24 \tilde{\mu} \beta_{3}}, \alpha_{1} \geq 0, \beta_{3} \geq 0, \beta_{1}=0=\beta_{2}$,

Equation (1) implies

$\tau^{*}=-p I+\tilde{\mu} \hat{A}_{1}^{*}+\alpha_{1}^{*} \hat{A}_{1}^{*}+\alpha_{2}^{*} \hat{A}_{2}^{* 2}+\beta_{3}^{*}\left(\operatorname{Tr} \hat{A}_{1}^{* 2}\right) \hat{A}_{1}^{*}$,

where $\operatorname{Tr}$ shows the trace.

The governing equations for (MHD-TGNFM) can be shown as follows [68]:

$\frac{\partial u}{\partial x}+\frac{\partial v}{\partial y}=0$

$$
\begin{aligned}
u \frac{\partial u}{\partial x}+v \frac{\partial u}{\partial y}= & v \frac{\partial^{2} u}{\partial y^{2}}+\frac{\alpha_{1}}{\rho}\left(\begin{array}{c}
u \frac{\partial^{3} u}{\partial x \partial y^{2}}+3 \frac{\partial u}{\partial y} \frac{\partial^{2} u}{\partial x \partial y} \\
+\frac{\partial u}{\partial x} \frac{\partial^{2} u}{\partial y^{2}}+v \frac{\partial^{3} u}{\partial y^{3}}
\end{array}\right) \\
& +2 \frac{\alpha_{2}}{\rho} \frac{\partial u}{\partial y} \frac{\partial^{2} u}{\partial x \partial y} \\
& +6 \frac{\beta}{\rho}\left(\left(\frac{\partial u}{\partial y}\right)^{2} \frac{\partial^{2} u}{\partial y^{2}}\right)-\sigma^{*} \frac{B_{0}^{2}}{\rho f} u
\end{aligned}
$$

$$
\begin{aligned}
u \frac{\partial T}{\partial x}+v \frac{\partial T}{\partial y}= & \alpha \frac{\partial^{2} T}{\partial y^{2}} \\
& +\frac{(\rho C)_{\mathrm{p}}}{(\rho C)_{\mathrm{f}}}\left(D_{\mathrm{B}}\left(\frac{\partial T}{\partial y} \frac{\partial C}{\partial y}\right)+\frac{D_{\mathrm{T}}}{T_{\infty}}\left(\frac{\partial T}{\partial y}\right)^{2}\right),
\end{aligned}
$$

$$
\begin{aligned}
u \frac{\partial C}{\partial x}+v \frac{\partial C}{\partial y}= & D_{\mathrm{B}}\left(\frac{\partial^{2} C}{\partial y^{2}}\right)+\frac{D_{\mathrm{T}}}{T_{\infty}}\left(\frac{\partial^{2} T}{\partial y^{2}}\right) \\
& -K_{\mathrm{r}}^{2}\left(C-C_{\infty}\right) \exp \left(\frac{-E_{\mathrm{a}}}{\kappa T}\right)\left(\frac{T}{T_{\infty}}\right)^{n},
\end{aligned}
$$

where the activation energy is $E_{a}$, the Boltzmann constant is $\kappa=8.61 \times 10^{-5} \mathrm{eV} / \mathrm{K}$, reaction rate is $K_{r}^{2}$, fitted rate constant is $n$, where the range of $\mathrm{n}$ is $-1<n<1$.

$K_{\mathrm{r}}^{2}\left(C-C_{\infty}\right) \exp \left(\frac{-E_{\mathrm{a}}}{\kappa T}\right)\left(\frac{T}{T_{\infty}}\right)^{n}$ is the modified Arrhenius equation. 
Boundary conditions are the following,

$u=u_{\mathrm{w}}(x)=a x^{\mathrm{m}}, v=0$,

$-k \frac{\partial T}{\partial y}=h_{1}\left(T_{f}-T\right)$

$-D_{\mathrm{B}} \frac{\partial C}{\partial y}=h_{2}\left(C_{\mathrm{f}}-C\right)$ at $y=0$

$u \rightarrow 0, T \rightarrow T_{\infty}, C \rightarrow C_{\infty}$ as $y \rightarrow \infty$

where $u$ and $v$ are the velocity components on the $(x, y)$ co-ordinates, respectively, dynamic viscosity is $\mu$, kinematic viscosity is represented by $v=\frac{\mu}{\rho f}$, $\rho$ f represents the density of ordinary liquid, $\alpha_{1}, \alpha_{2}$ and $\beta$ are representing the material parameters, temperature is $T$, electric conductivity is $\sigma^{*}, \mathrm{k}$ is the thermal conductivity, fluid's thermal diffusivity is $\alpha$, where $\alpha=\frac{k}{(\rho C)_{\mathrm{f}}}$, the fluid's heat capacity is $(\rho C)_{\mathrm{f}}$,effective heat potential of nanoparticles is represented by $(\rho C)_{\mathrm{p}}$, thermophoresis and Brownian diffusion coefficients are represented by $D_{\mathrm{T}}$ and $D_{\mathrm{B}}$, concentration is represented by $\mathrm{C}$, the temperature far away from sheet is represented by $T_{\infty}, C_{\infty}$ stands for ambient temperature, reaction rate is represented by $K_{r}$, fitted rate constant is n, variable heat transfer coefficient is $h_{1}$ and variable mass transfer coefficient is $h_{2}$, where $h_{1}=h_{\mathrm{t}} x^{\frac{m-1}{2}}$ and $h_{2}=h_{\mathrm{m}} x^{\frac{m-1}{2}}$, now $\theta^{\prime \prime}+\operatorname{Pr}\left(f \theta^{\prime}+\mathrm{Nt} \theta^{\prime 2}+\mathrm{Nb} \theta^{\prime} \phi^{\prime}\right)=0$

$$
\begin{aligned}
& \phi^{\prime \prime}+\operatorname{Scf} \phi^{\prime}+\left(\frac{\mathrm{Nt}}{\mathrm{Nb}}\right) \theta^{\prime \prime} \\
& -\left(\frac{2}{m+1}\right) \operatorname{Sc} \sigma(1+\theta \delta)^{n} \exp \left(\frac{-E}{1+\theta \delta}\right) \phi=0,
\end{aligned}
$$

$f(0)=0, f^{\prime}(0)=1$,

$\theta^{\prime}(0)=-\gamma_{1}(1-\theta(0))$,

$\phi^{\prime}(0)=-\gamma_{2}(1-\phi(0))$,

$f^{\prime}(\infty) \rightarrow 0, \quad \theta(\infty) \rightarrow 0, \quad \phi(\infty) \rightarrow 0$,

where the material parameters of nanofluid (third grade) are represented by $\chi, \epsilon_{1}, \epsilon_{2}$ and $\epsilon_{3}, \operatorname{Re}_{x}$ and $\mathrm{Ha}$ represent the local Reynolds number and the local Hartmann number, the Prandtl number is Pr, Brownian and thermophoresis parameters are represented by $\mathrm{Nb}$ and $\mathrm{Nt}$, dimensionless activation energy is $E$, Schmidt number is Sc, local chemical reaction number is represented by $\sigma$, temperature difference parameter is represented by $\delta$, thermal and concentration Biot number is represented by $\gamma_{1}$ and $\gamma_{2}$. These parameters are as follows:

$$
\begin{aligned}
& \epsilon_{1}=\frac{\alpha_{1} a x^{m-1}}{\mu}, \epsilon_{2}=\frac{\alpha_{2} a x^{m-1}}{\mu}, \epsilon_{3}=\frac{\beta a^{2} x^{2(m-1)}}{\mu}, \operatorname{Re}_{x}=\frac{a x^{m+1}}{v}, H a^{2}=\frac{\sigma^{*} B_{0}^{2}}{a \rho f x^{m-1}}, \\
& \operatorname{Pr}=\frac{v}{\alpha}, \mathrm{Nb}=\frac{(\rho C)_{\mathrm{p}} D_{\mathrm{B}}\left(C_{\mathrm{f}}-C_{\infty}\right)}{(\rho C)_{\mathrm{f}} v}, \mathrm{Nt}=\frac{(\rho C)_{\mathrm{p}} D_{\mathrm{T}}\left(T_{\mathrm{f}}-T_{\infty}\right)}{(\rho C)_{\mathrm{f}} v T_{\infty}}, E=\frac{E_{\mathrm{a}}}{\kappa T_{\infty}}, \mathrm{Sc}=\frac{v}{D_{\mathrm{B}}}, \\
& \gamma_{1}=\frac{h_{t}}{k} \sqrt{\frac{2 v}{a(m+1)}}, \gamma_{2}=\frac{h_{\mathrm{m}}}{D_{\mathrm{B}}} \sqrt{\frac{2 v}{a(m+1)}}, \delta=\frac{\left(T_{\mathrm{f}}-T_{\infty}\right)}{T_{\infty}}, \sigma=\frac{K_{\mathrm{r}}^{2}}{a x^{m-1}},
\end{aligned}
$$

$$
\begin{aligned}
& u=a x^{m} f^{\prime}(\chi), v=-\left(\frac{a v(m+1)}{2}\right)^{\frac{1}{2}} x^{\frac{m-1}{2}}\left(f(\chi)+\chi \frac{m-1}{m+1} f^{\prime}(\chi)\right), \\
& \phi(\chi)=\frac{C-C_{\infty}}{C_{\mathrm{f}}-C_{\infty}}, \theta(\chi)=\frac{T-T_{\infty}}{T_{\mathrm{f}}-T_{\infty}}, \chi=x^{\frac{m-1}{2}}\left(\frac{a(m+1)}{2 v}\right)^{\frac{1}{2}} y,
\end{aligned}
$$

\section{Solution Methodology}

The MATLAB command 'nftool' is used to execute the technique of backpropagation in artificial neural network

Now from Eqs. (7)-(11), take the following forms [68]

$$
\begin{aligned}
& f^{\prime \prime \prime}+f f^{\prime \prime}-\frac{2 m}{m+1}\left(f^{\prime}\right)^{2}+\epsilon_{1}\left((3 m-1) f^{\prime} f^{\prime \prime \prime}+2(m-1) \chi\right) f^{\prime \prime} f^{\prime \prime \prime}-\left(\frac{m+1}{2}\right) f f^{(i v)}+\frac{3(3 m-1)}{2}\left(f^{\prime \prime}\right)^{2} \\
& +\epsilon_{2}\left((3 m-1)\left(f^{\prime \prime}\right)^{2}+(m-1) f^{\prime \prime} f^{\prime \prime \prime} \chi\right)+6 \epsilon_{3} \operatorname{Re}_{x}\left(\frac{m+1}{2}\right)\left(f^{\prime \prime}\right)^{2} f^{\prime \prime \prime}-\left(\frac{2}{m+1}\right) f^{\prime} \mathrm{Ha}^{2}=0,
\end{aligned}
$$


Table 1 Values of constant parameters

\begin{tabular}{cccccccccc}
\hline$\epsilon_{1}$ & $\epsilon_{2}$ & $\epsilon_{3}$ & $\mathrm{Re}_{x}$ & $\mathrm{Nb}$ & $\mathrm{Nt}$ & $\delta$ & $\mathrm{m}$ & $\mathrm{E}$ & $\mathrm{n}$ \\
\hline 0.0 & 0.2 & 0.2 & 0.1 & 0.3 & 0.1 & 0.3 & 1.5 & 0.5 & 0.5 \\
\hline
\end{tabular}

using the Levenberg-Marquardt technique (BANN-LMT). The following figure shows the neural network for (BANNLMT).

There are six variations for MHD-TGNFM. This article discusses the variation of local Hartman number (Ha), Prandtl number $(\operatorname{Pr})$, local chemical reaction parameter $(\sigma)$, Schmidt number (Sc), thermal Biot number $\left(\gamma_{1}\right)$ and concentration Biot number $\left(\gamma_{2}\right)$. Every scenario has further four cases. There are 10 physical quantities that have the fixed values for every scenario. By the variation of six physical quantities, the impact on velocity, concentration and temperature distribution is examined in this study. Now the values of the other parameters are given in Table 1.

The inputs for the dataset are between 0 and 6 , and the time interval is 0.06 with hiding 10 neurons. Utilizing the technique of Adam numerical method with the help of 'NDSolve' in Wolfram Mathematica with the variations of local Hartman number, Prandtl number, local chemical reaction parameter, Schmidt number, thermal Biot number and concentration Biot number in MHD-TGNFM. These variations are listed in Table 2, whereas Table 1 shows the value of the parameters which have the constant values. And these parameters are material parameter, Brownian movement parameter, thermophoresis parameter, temperature difference parameter, fitted rate constant, activation energy and Reynolds number.

\section{Analyzation and Discussion of Result}

To compute the dataset for BANN-LMT, the six different scenarios are discussed and that variations are for local Hartman number (Ha), Schmidt number (Sc), thermal Biot number $\left(\gamma_{1}\right)$, Prandtl number $(\mathrm{Pr})$, local chemical reaction parameter $(\sigma)$ and concentration Biot number $\left(\gamma_{2}\right)$. Here the Prandtl number shows the ratio between momentum diffusivity and thermal diffusivity, where the Schmidt number is the ratio between the momentum diffusivity and the mass diffusivity. The ratio is between the heat transfer resistances in a body and at the surface of the body.

These variations are for the four cases of MHD-TGNFM over a stretching sheet. Adam numerical method is used to compute the dataset for $f^{\prime}(\chi), \theta(\chi)$ and $\phi(\chi)$. The input is between 0 and 6 with 0.06 step size for the four cases of the scenarios of BANN-LMT of MHD-TGNFM. MATLAB built command 'nftool' is used to determine the solution for the third-grade nanofluid model (MHD-TGNFM). The dataset for $f^{\prime}(\chi), \theta(\chi)$ and $\phi(\chi)$ is computed for 101 points, from
Table 2 Scenarios for MHD-TGNFM

\begin{tabular}{|c|c|c|c|c|c|c|c|}
\hline \multirow[t]{2}{*}{ Scenarios } & \multirow[t]{2}{*}{ Cases } & \multicolumn{6}{|c|}{ Physical quantities } \\
\hline & & $\gamma_{2}$ & $\gamma_{1}$ & Ha & $\operatorname{Pr}$ & $\mathrm{Sc}$ & $\sigma$ \\
\hline \multirow[t]{4}{*}{01} & 1 & 0.1 & 0.4 & 0.1 & 1.0 & 1.0 & 0.3 \\
\hline & 2 & 0.3 & 0.4 & 0.1 & 1.0 & 1.0 & 0.3 \\
\hline & 3 & 0.6 & 0.4 & 0.1 & 1.0 & 1.0 & 0.3 \\
\hline & 4 & 0.9 & 0.4 & 0.1 & 1.0 & 1.0 & 0.3 \\
\hline \multirow[t]{4}{*}{02} & 1 & 0.4 & 0.5 & 0.1 & 1.0 & 1.0 & 0.3 \\
\hline & 2 & 0.4 & 0.7 & 0.1 & 1.0 & 1.0 & 0.3 \\
\hline & 3 & 0.4 & 0.9 & 0.1 & 1.0 & 1.0 & 0.3 \\
\hline & 4 & 0.4 & 1.1 & 0.1 & 1.0 & 1.0 & 0.3 \\
\hline \multirow[t]{4}{*}{03} & 1 & 0.4 & 0.4 & 0.0 & 1.0 & 1.0 & 0.3 \\
\hline & 2 & 0.4 & 0.4 & 0.45 & 1.0 & 1.0 & 0.3 \\
\hline & 3 & 0.4 & 0.4 & 0.7 & 1.0 & 1.0 & 0.3 \\
\hline & 4 & 0.4 & 0.4 & 0.9 & 1.0 & 1.0 & 0.3 \\
\hline \multirow[t]{4}{*}{04} & 1 & 0.4 & 0.4 & 0.1 & 0.8 & 1.0 & 0.3 \\
\hline & 2 & 0.4 & 0.4 & 0.1 & 1.0 & 1.0 & 0.3 \\
\hline & 3 & 0.4 & 0.4 & 0.1 & 1.2 & 1.0 & 0.3 \\
\hline & 4 & 0.4 & 0.4 & 0.1 & 1.4 & 1.0 & 0.3 \\
\hline \multirow[t]{4}{*}{05} & 1 & 0.4 & 0.4 & 0.1 & 1.0 & 1.2 & 0.3 \\
\hline & 2 & 0.4 & 0.4 & 0.1 & 1.0 & 1.4 & 0.3 \\
\hline & 3 & 0.4 & 0.4 & 0.1 & 1.0 & 1.6 & 0.3 \\
\hline & 4 & 0.4 & 0.4 & 0.1 & 1.0 & 1.8 & 0.3 \\
\hline \multirow[t]{4}{*}{06} & 1 & 0.4 & 0.4 & 0.1 & 1.0 & 1.0 & 0.4 \\
\hline & 2 & 0.4 & 0.4 & 0.1 & 1.0 & 1.0 & 0.6 \\
\hline & 3 & 0.4 & 0.4 & 0.1 & 1.0 & 1.0 & 0.8 \\
\hline & 4 & 0.4 & 0.4 & 0.1 & 1.0 & 1.0 & 1.0 \\
\hline
\end{tabular}

which $10 \%$ points are used for testing, $10 \%$ for validation and $80 \%$ for training as shown in Fig. 1. And Fig. 2 shows the flowchart. Figure 3 depicts the performance of each third instance in all BANN-LMT scenarios. And the training state is shown in Fig. 4. The fitness and the error histogram are represented in Fig. 5, and Fig. 6 shows the regression graphs for every third instance of all the scenarios. Table 3 represents the data for training, validation, testing, epochs, performance, $\mathrm{Mu}$ and time taken.

Velocity profile decreases for the increasing values of local Hartman number. The temperature profile increases when there is an increase in thermal Biot number and the local Hartmann number, whereas the increase in the values of Prandtl number causes the drop in temperature profile. The concentration profile increases with the increase in concentration Biot number and the local Hartmann number. And it decreases with the increase in Schmidt number and the local chemical reaction parameter. Figure 7a shows the impact of the variation of $\mathrm{Ha}$ on $f^{\prime}(\chi)$ and $7 \mathrm{~b}$ shows the absolute error about $10^{-3}$ to $10^{-7}$. Figure $8 \mathrm{a}, \mathrm{c}$ and e depicts the variation of thermal Biot number, local Hartman number and Prandtl 
Fig. 1 The design of neural network for (MHD-TGNFM)

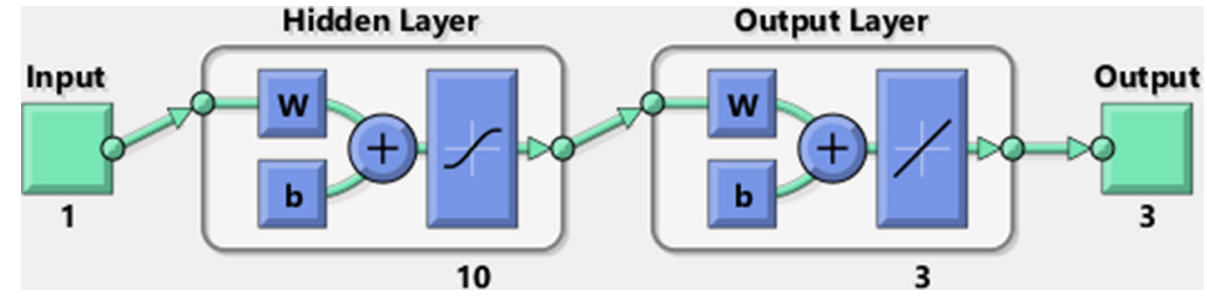

Fig. 2 Flowchart of MHD-TGNFM
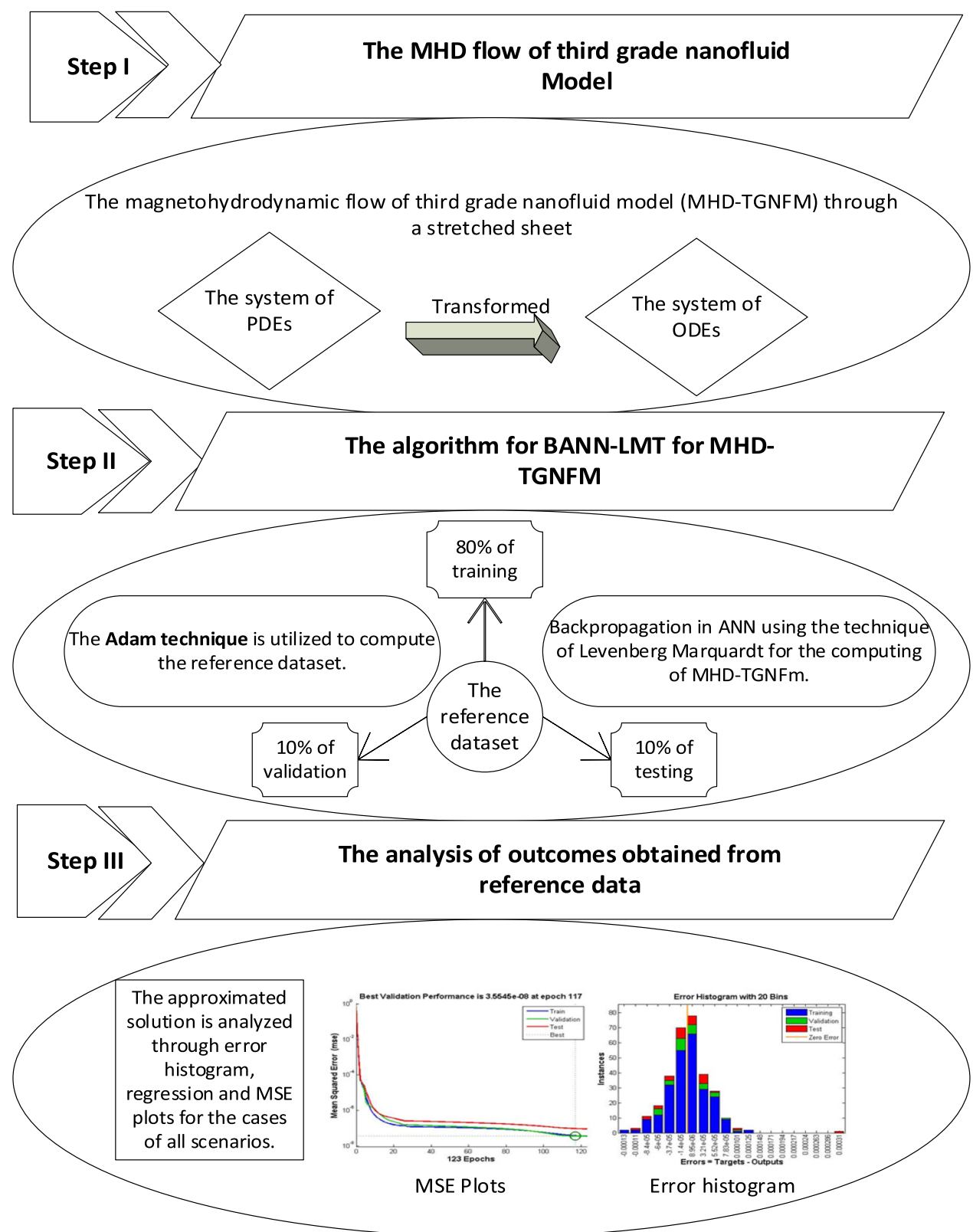

number on the temperature profile. Figure $8 b, d$ and $f$ shows the absolute error about $10^{-3}$ to $10^{-7}$. Figure $9 \mathrm{a}, \mathrm{c}$, e and $\mathrm{g}$ shows the variation of concentration Biot number $\left(\gamma_{2}\right)$, local Hartman number (Ha), Schmidt number (Sc) and local chemical reaction parameter $(\sigma)$ on the concentration profile. Figure $9 \mathrm{~b}, \mathrm{~d}, \mathrm{f}$ and $\mathrm{h}$ shows the absolute error about $10^{-3}$ to $10^{-6}, 10^{-3}$ to $10^{-7}, 10^{-2}$ to $10^{-7}$ and $10^{-2}$ to $10^{-7}$.
In the literature above mentioned in introduction, the researchers used NDSolve and many other techniques to compute the solution, but this paper examined MHDTGNFM by utilizing BANN-LMT, where the LevenbergMarquardt technique is a supervised learning technique in which the input and output are given. The performance, regression, fitness, error histogram and training state plots 


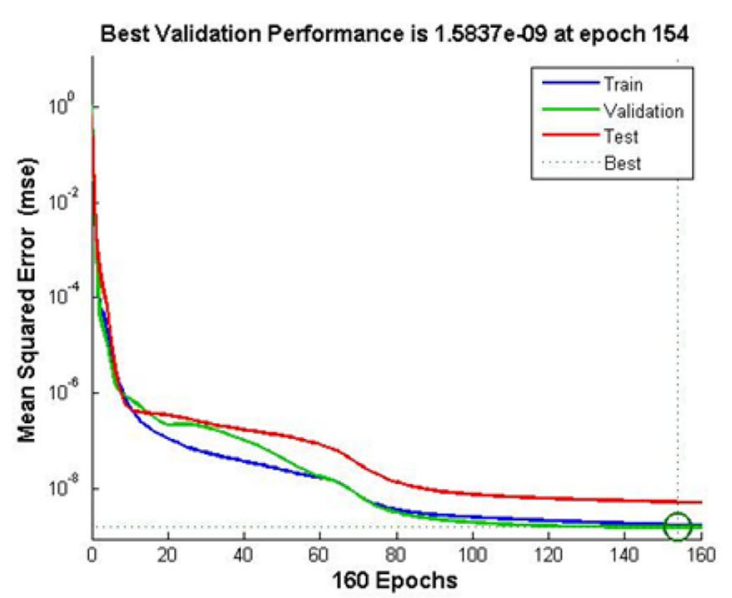

MSE Results: Scenario I, Case III

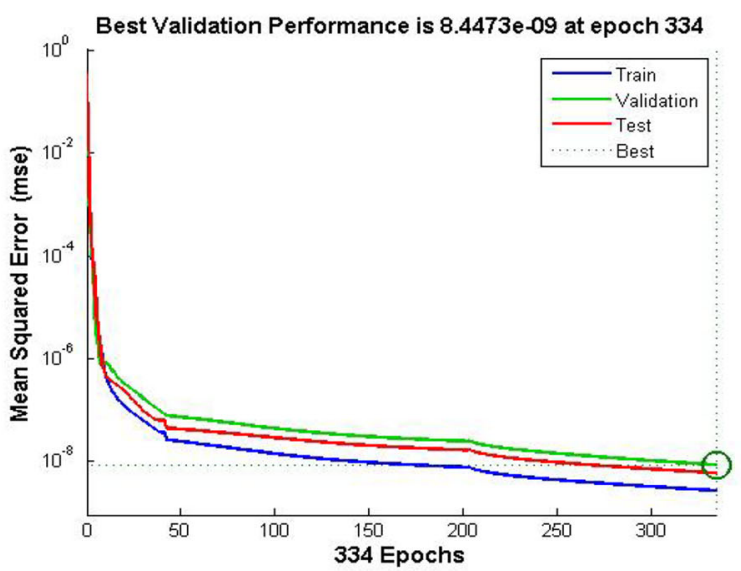

MSE Results: Scenario III, Case III

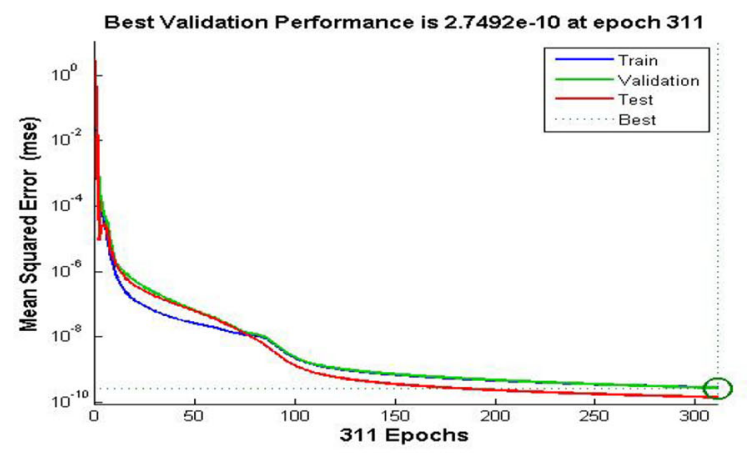

MSE Results: Scenario V, Case III

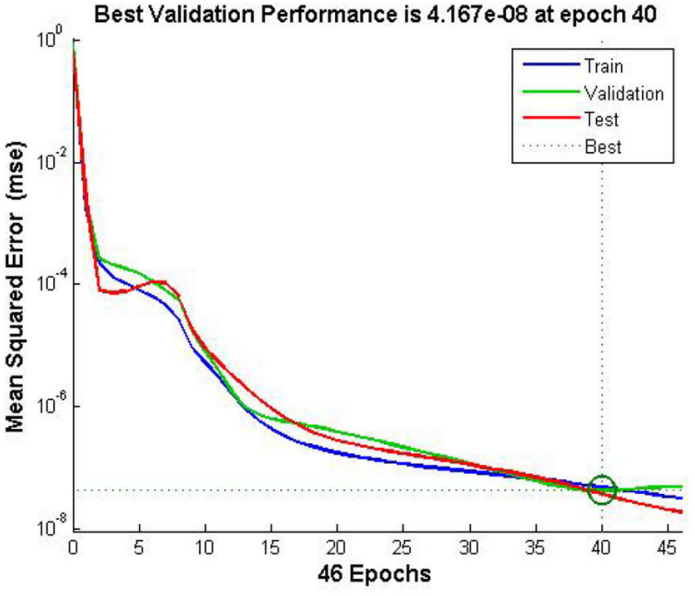

MSE Results: Scenario II, Case III

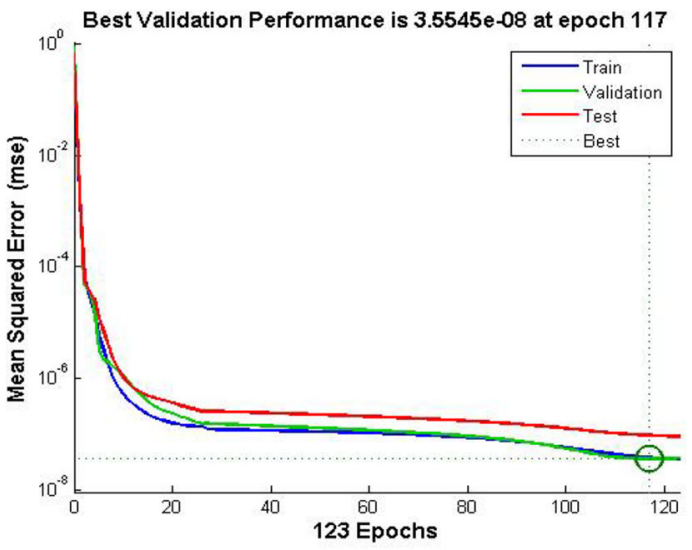

MSE Results: Scenario IV, Case III

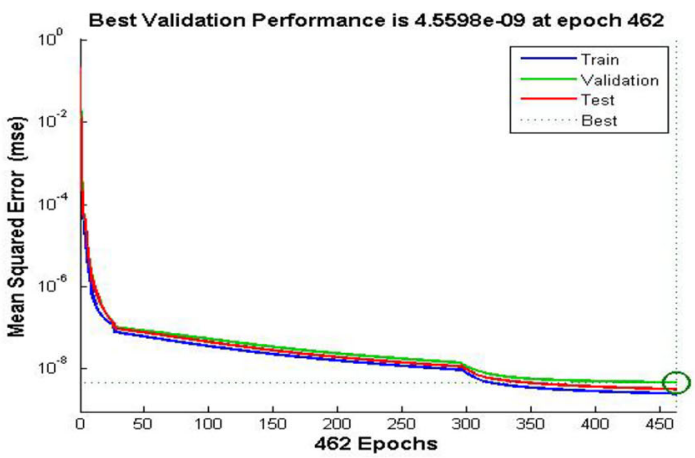

MSE Results: Scenario VI, Case III

Fig. 3 The performance plots of BANN-LMT for third instance of all events of MHD-TGNFM

can easily be computed with this technique and give a close approximated solution plots and the absolute error plots.

Artificial intelligence-based neural networks are frequently used to solve different flow problems due to their effectiveness and worth. It has many applications in different research models. Some recent models using the AI-based neural techniques are COVID 19 model [69], medicines [70], urological diseases model [71], Emden-Fowler model [72], dust density model [73], pathology [74], and dentistry [75].

\subsection{Impact on Velocity Profile $f^{\prime}(\chi)$}

MATLAB is used to analyze the results of BANN-LMT for the investigation of the impact of variation of local Hartman 


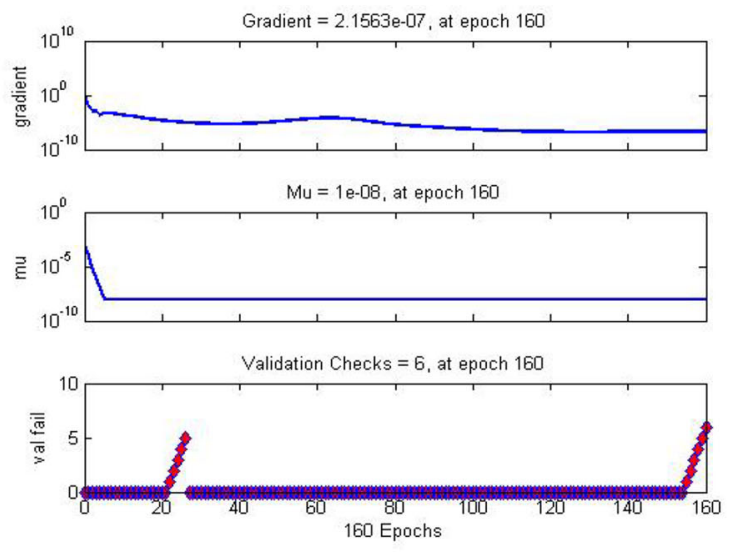

Transition Plots: Scenario I, Case III
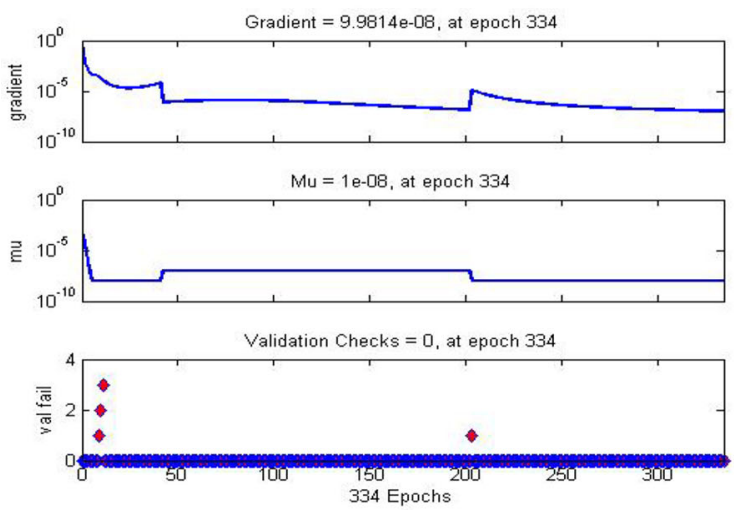

Transition Plots: Scenario III, Case III
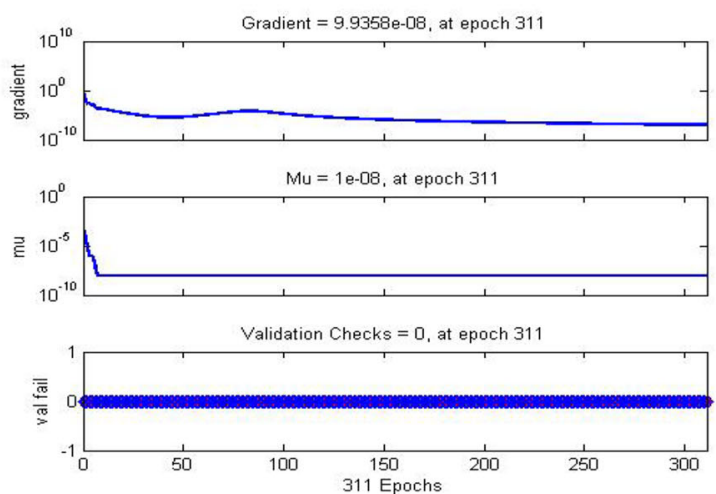

Transition Plots: Scenario V, Case III
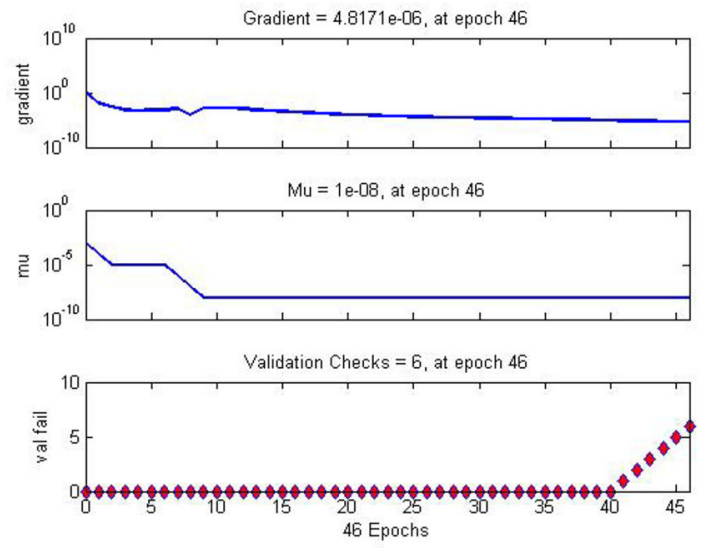

Transition Plots: Scenario II, Case III
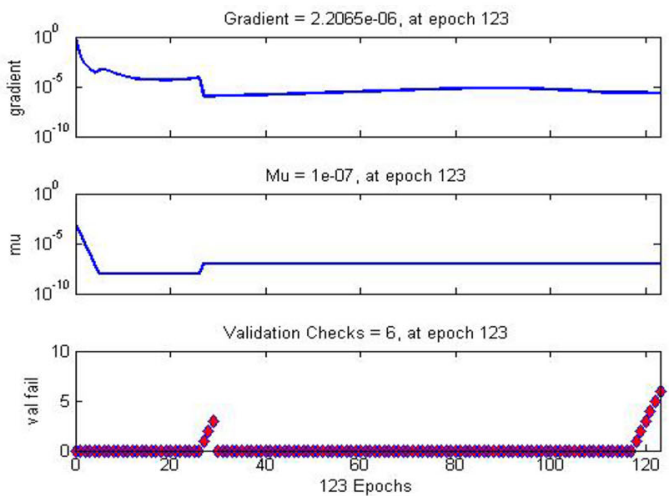

Transition Plots: Scenario IV, Case III
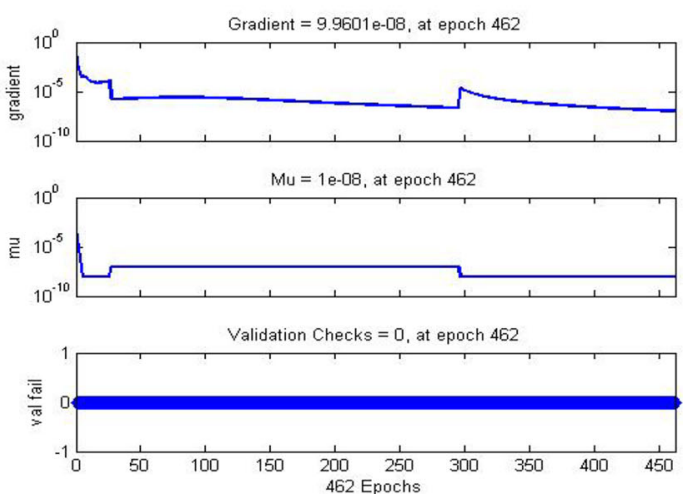

Transition Plots: Scenario VI, Case III

Fig. 4 Transition plots of BANN-LMT for third instance of all events of MHD-TGNFM

number (Ha) on the velocity profile $f^{\prime}(\chi)$. Figure 7 a shows the impact of the variation of Ha on $f^{\prime}(\chi)$ and $7 \mathrm{~b}$ shows the absolute error about $10^{-3}$ to $10^{-7}$. It can be easily seen that the velocity distribution shows a decrease with the increase in local Hartman number.

\subsection{Impact on Temperature Profile $\theta(\chi)$}

MATLAB analyzed the results of BANN-LMT to determine the effect of variation of local Hartman number (Ha), Prandtl number $(\operatorname{Pr})$ and thermal Biot number $\left(\gamma_{1}\right)$ on the temperature profile. Figure $8 \mathrm{a}, \mathrm{c}$ and e depicts the variation of thermal Biot number, local Hartman number and Prandtl number on the temperature profile. Figure $8 \mathrm{~b}$, $\mathrm{d}$ and $\mathrm{f}$ shows the absolute 

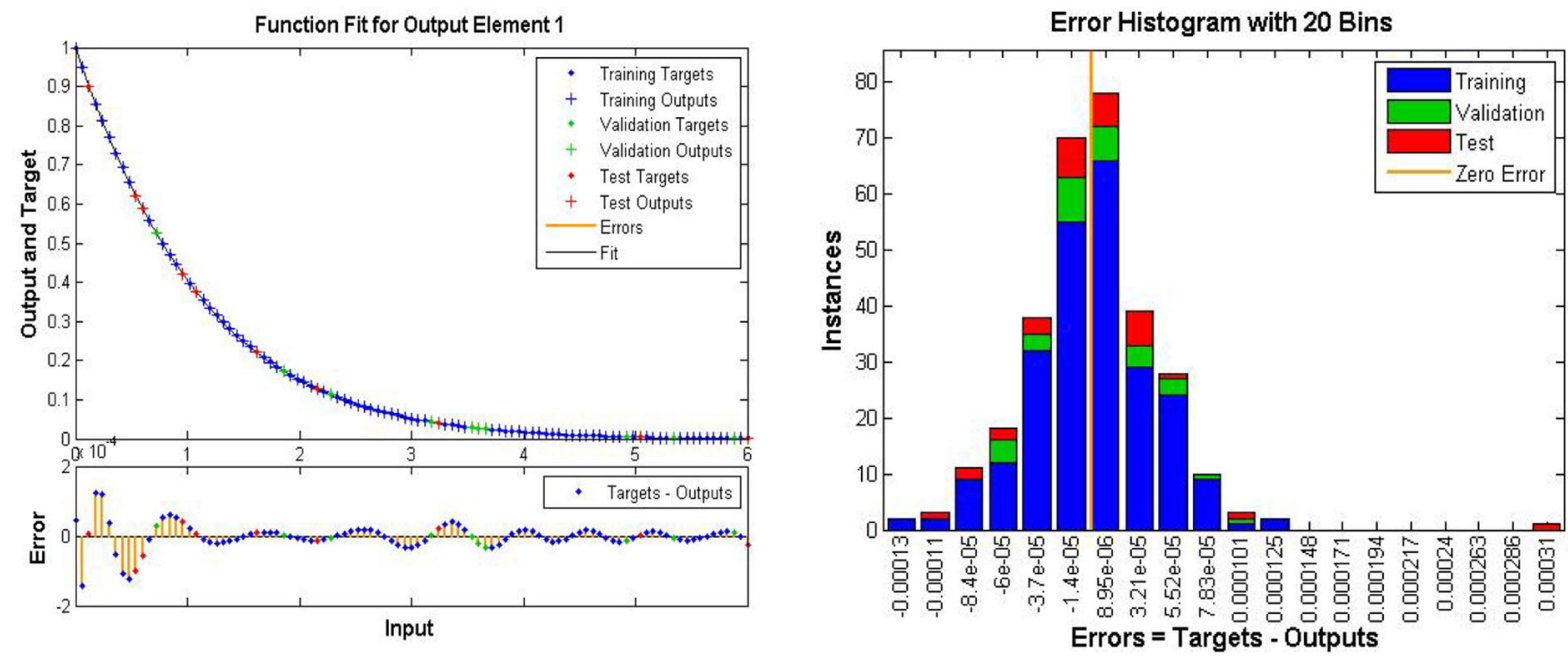

Fitness and error histogram: Scenario I, Case III
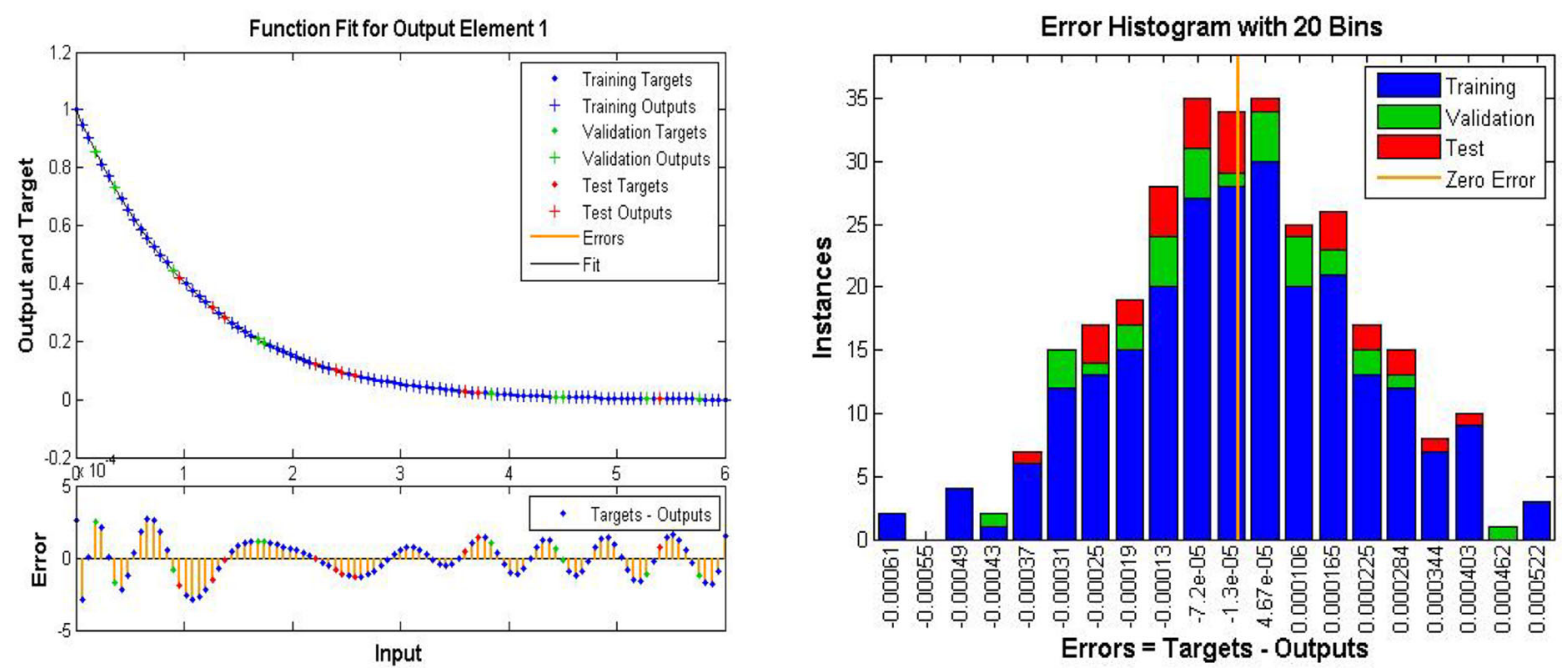

Fitness and error histogram: Scenario II, Case III
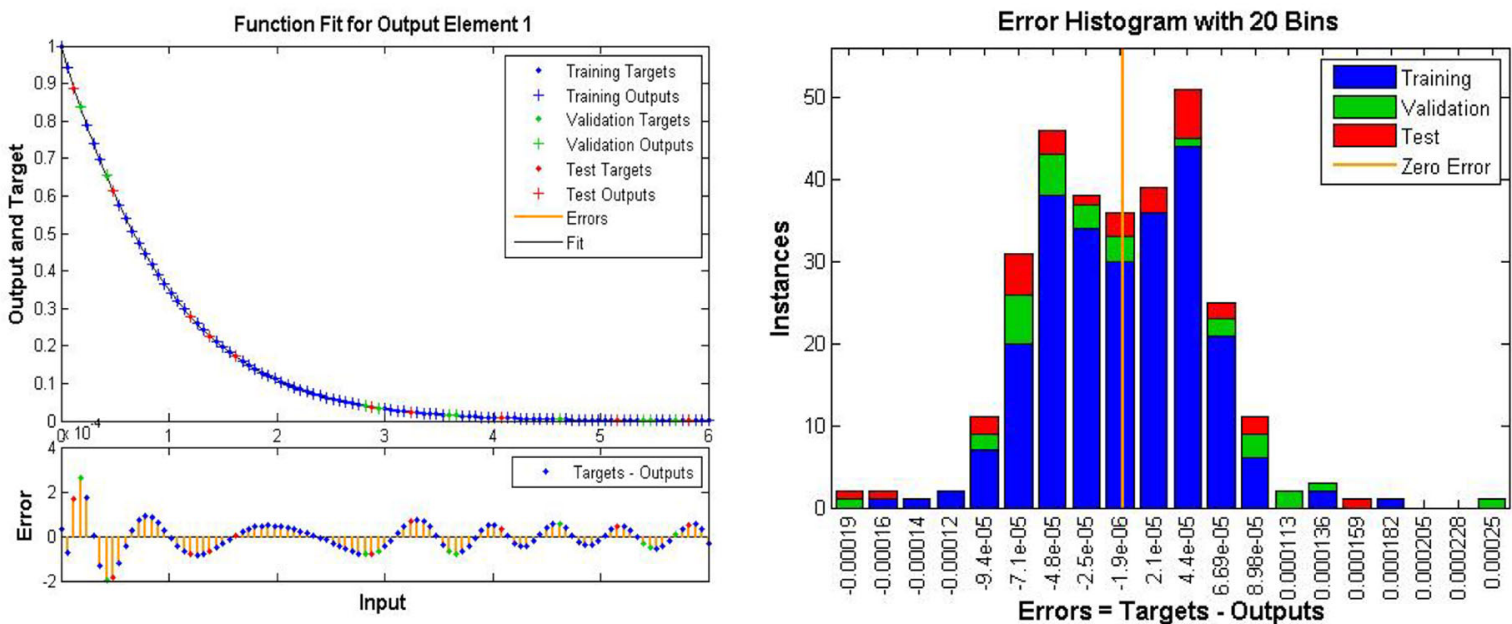

Fitness and error histogram: Scenario III, Case III

Fig. 5 Fitness and error histogram plots of BANN-LMT for third instance of all events of MHD-TGNFM 

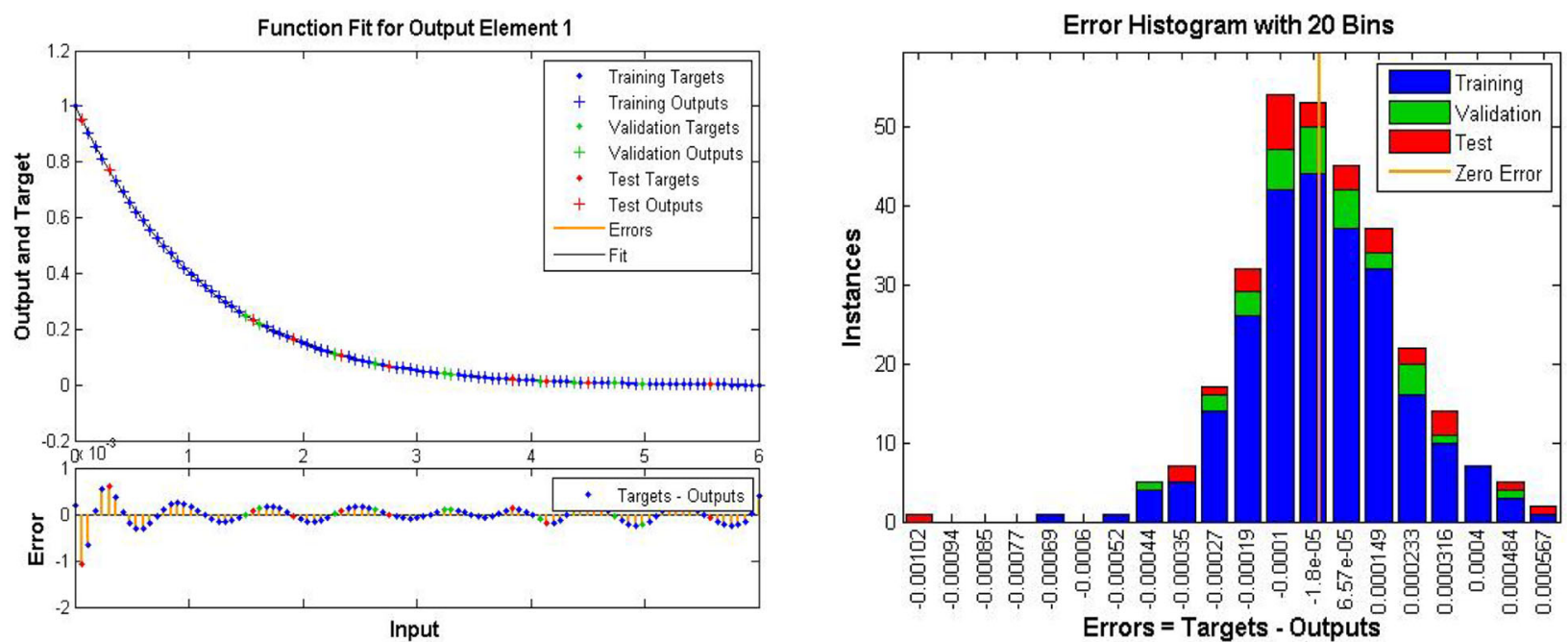

Fitness and error histogram: Scenario IV, Case III
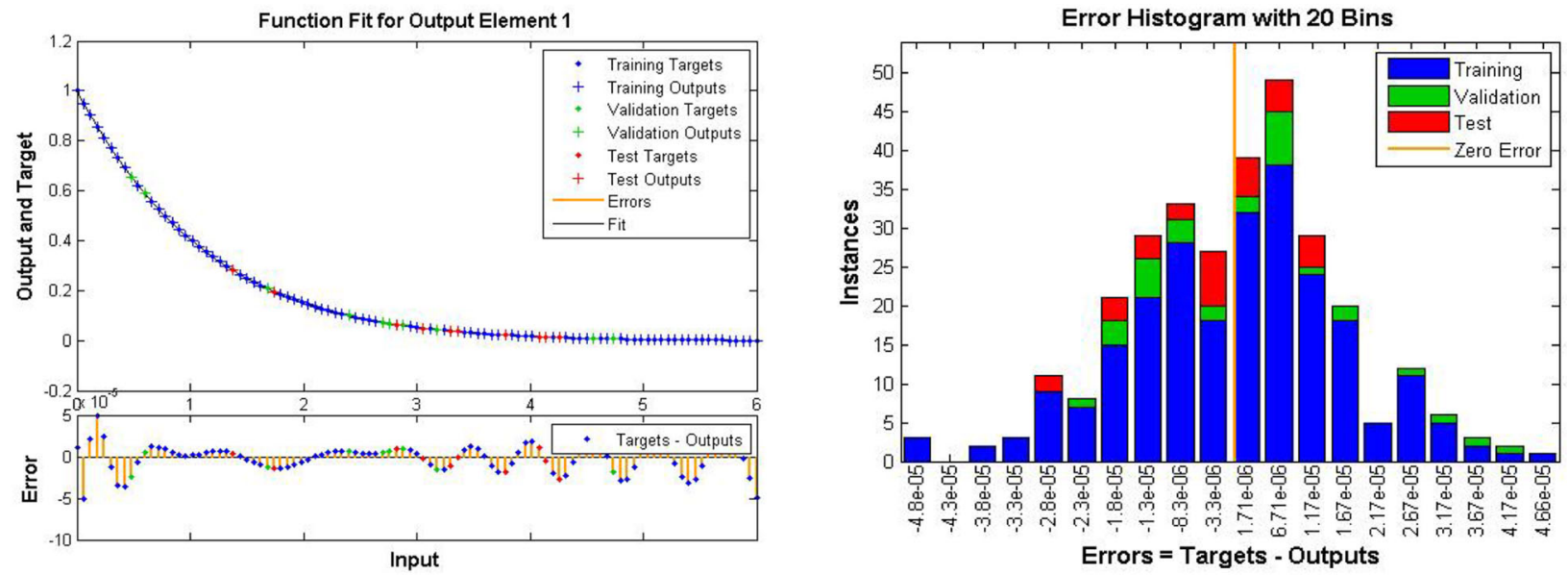

Fitness and error histogram: Scenario V, Case III
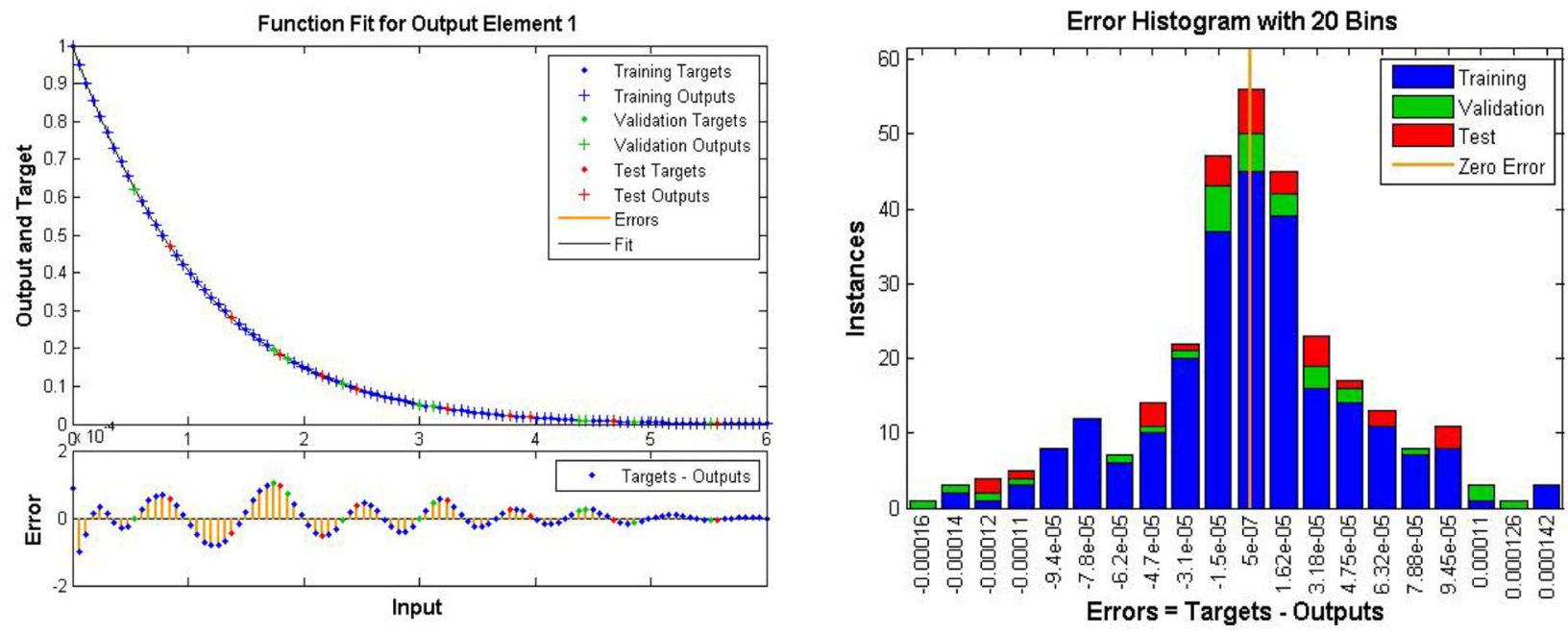

Fitness and error histogram: Scenario VI, Case III

Fig. 5 continued 
Fig. 6 Regression plots of BANN-LMT for third instance of all events of MHD-TGNFM
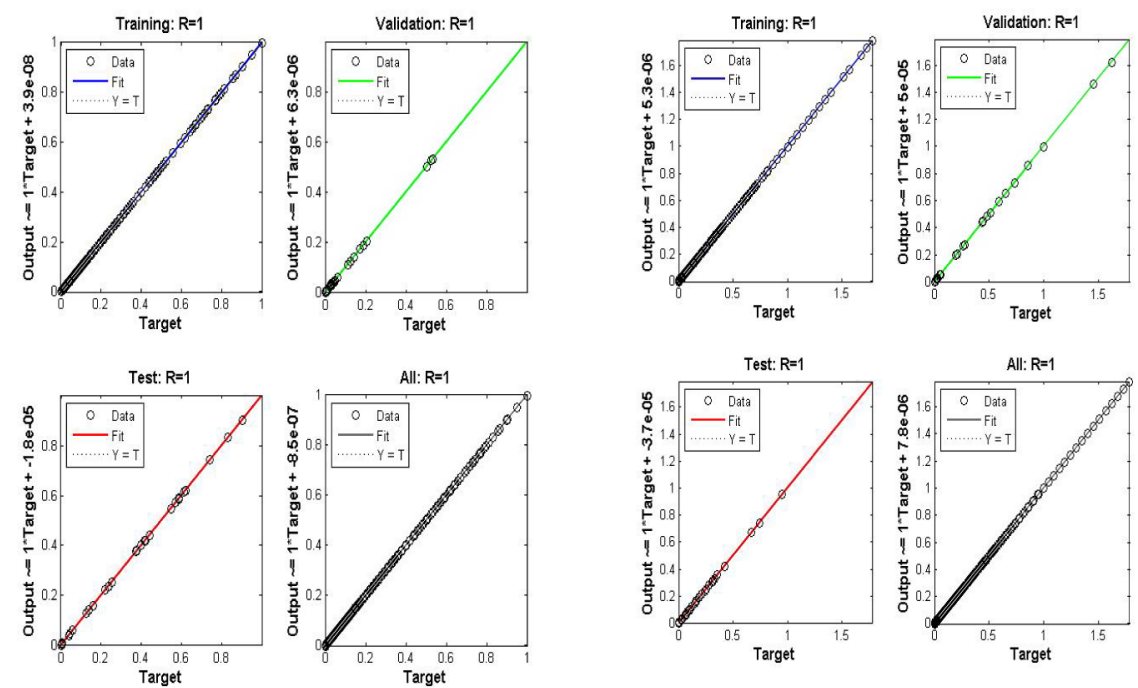

Regression Plot: Scenario I
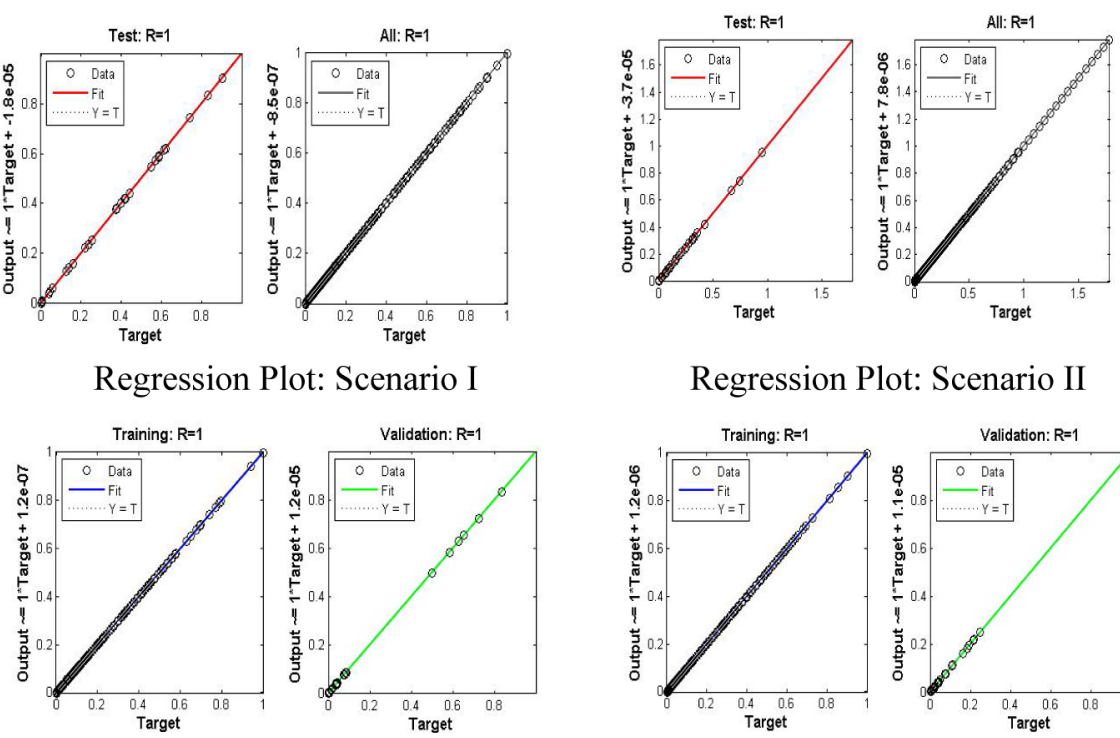

Regression Plot: Scenario II
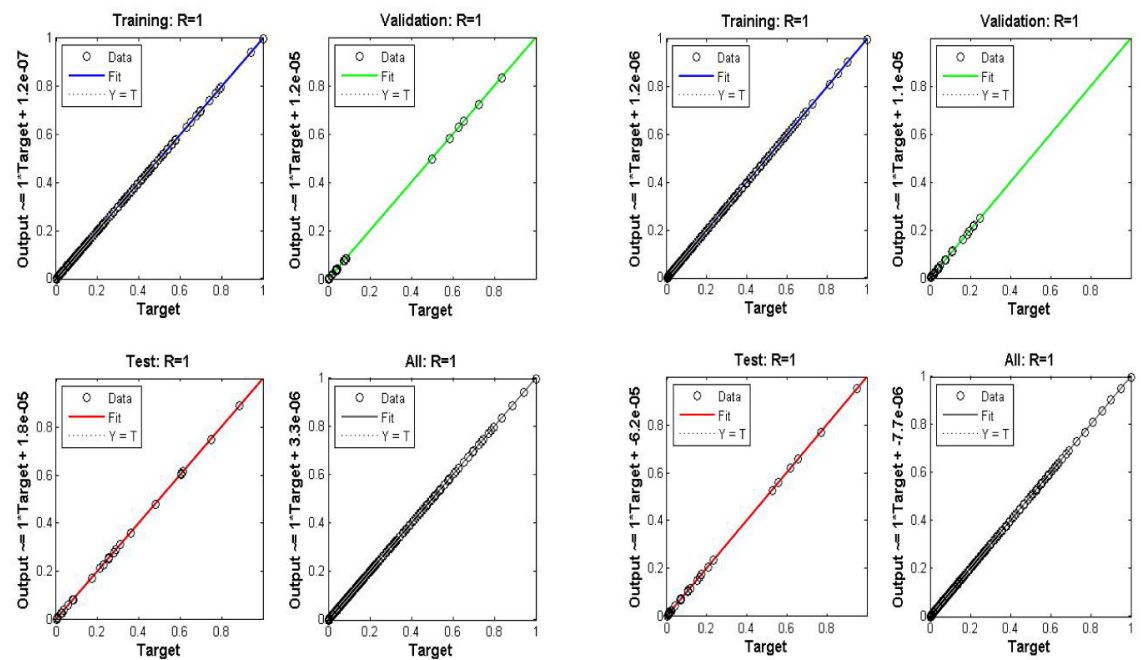

Regression Plot: Scenario III
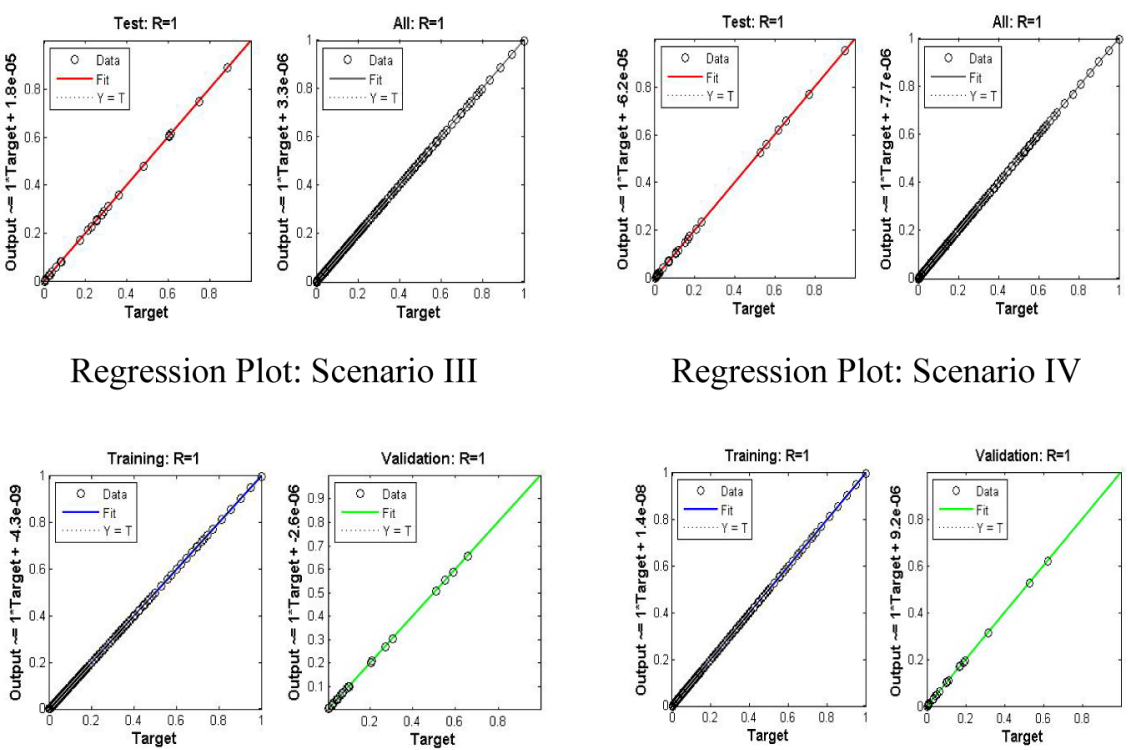

Regression Plot: Scenario IV
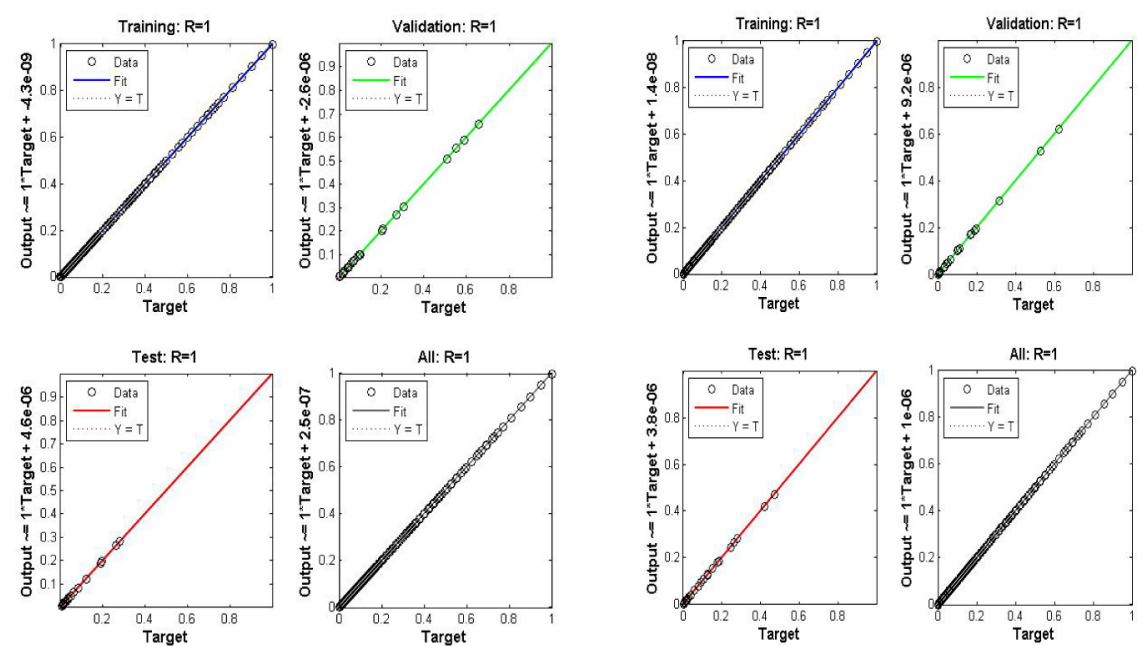

Regression Plot: Scenario V
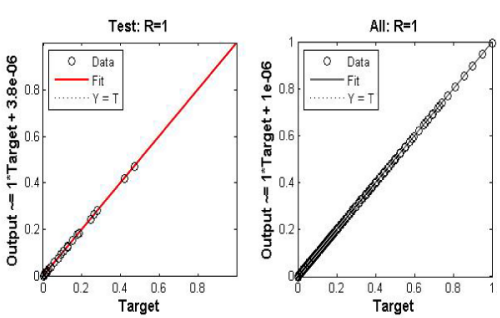

Regression Plot: Scenario VI 
Table 3 Outcomes of BANN-LMT of MHD-TGNFM

\begin{tabular}{|c|c|c|c|c|c|c|c|c|c|}
\hline \multirow[t]{2}{*}{ Scenario } & \multirow[t]{2}{*}{ Instances } & \multicolumn{3}{|l|}{ MSE data } & \multirow[t]{2}{*}{ Performance } & \multirow[t]{2}{*}{ Gradient } & \multirow[t]{2}{*}{$\mathrm{Mu}$} & \multirow[t]{2}{*}{ Final epoch } & \multirow[t]{2}{*}{ Time (s) } \\
\hline & & Training & Validation & Testing & & & & & \\
\hline \multirow[t]{4}{*}{1} & 1 & $2.44 \mathrm{E}-09$ & $1.34 \mathrm{E}-07$ & $2.71 \mathrm{E}-09$ & $2.44 \mathrm{E}-09$ & $8.90 \mathrm{E}-09$ & $1.00 \mathrm{E}-08$ & 185 & 4 \\
\hline & 2 & $1.20 \mathrm{E}-09$ & $2.66 \mathrm{E}-09$ & $1.62 \mathrm{E}-09$ & $1.20 \mathrm{E}-09$ & $9.91 \mathrm{E}-08$ & $1.00 \mathrm{E}-08$ & 173 & 3 \\
\hline & 3 & $1.75 \mathrm{E}-09$ & $1.58 \mathrm{E}-09$ & $5.26 \mathrm{E}-09$ & $1.69 \mathrm{E}-09$ & $2.16 \mathrm{E}-07$ & $1.00 \mathrm{E}-08$ & 160 & 2 \\
\hline & 4 & $8.08 \mathrm{E}-10$ & $1.31 E-09$ & $9.78 \mathrm{E}-10$ & $8.08 \mathrm{E}-10$ & $9.96 \mathrm{E}-08$ & $1.00 \mathrm{E}-08$ & 268 & 5 \\
\hline \multirow[t]{4}{*}{2} & 1 & $8.30 \mathrm{E}-10$ & $4.27 E-09$ & $1.08 \mathrm{E}-09$ & $8.30 \mathrm{E}-10$ & $9.97 \mathrm{E}-08$ & $1.00 \mathrm{E}-08$ & 534 & 9 \\
\hline & 2 & $5.47 \mathrm{E}-10$ & $3.43 E-11$ & $9.11 \mathrm{E}-10$ & $5.47 \mathrm{E}-10$ & $9.95 \mathrm{E}-08$ & $1.00 \mathrm{E}-08$ & 292 & 5 \\
\hline & 3 & $4.73 E-08$ & $4.17 E-08$ & $3.68 \mathrm{E}-08$ & $3.08 \mathrm{E}-08$ & $4.82 \mathrm{E}-06$ & $1.00 \mathrm{E}-08$ & 46 & $<1$ \\
\hline & 4 & $2.87 \mathrm{E}-08$ & $2.58 \mathrm{E}-08$ & $1.18 \mathrm{E}-07$ & $2.05 E-08$ & $1.01 \mathrm{E}-05$ & $1.01 \mathrm{E}-05$ & 45 & $<1$ \\
\hline \multirow[t]{4}{*}{3} & 1 & $7.35 E-11$ & $1.36 \mathrm{E}-10$ & $9.29 \mathrm{E}-11$ & $7.35 \mathrm{E}-11$ & $9.95 \mathrm{E}-08$ & $1.00 \mathrm{E}-09$ & 417 & $7 \mathrm{~s}$ \\
\hline & 2 & $1.66 \mathrm{E}-09$ & $7.30 \mathrm{E}-09$ & $7.64 \mathrm{E}-09$ & $1.66 \mathrm{E}-09$ & $9.46 \mathrm{E}-08$ & $1.00 \mathrm{E}-08$ & 186 & 3 \\
\hline & 3 & $2.66 \mathrm{E}-09$ & $8.44 \mathrm{E}-09$ & $5.86 \mathrm{E}-09$ & $2.66 \mathrm{E}-09$ & $9.98 \mathrm{E}-08$ & $1.00 \mathrm{E}-08$ & 334 & 5 \\
\hline & 4 & $3.57 \mathrm{E}-08$ & $4.84 \mathrm{E}-08$ & $3.11 \mathrm{E}-08$ & $2.90 \mathrm{E}-08$ & $7.07 \mathrm{E}-07$ & $1.00 \mathrm{E}-07$ & 50 & $<1$ \\
\hline \multirow[t]{4}{*}{4} & 1 & $2.27 \mathrm{E}-09$ & $3.35 E-09$ & $4.57 \mathrm{E}-09$ & $2.27 E-09$ & $9.97 \mathrm{E}-08$ & $1.00 \mathrm{E}-08$ & 571 & 10 \\
\hline & 2 & $1.61 \mathrm{E}-10$ & $8.62 E-09$ & $3.26 \mathrm{E}-10$ & $1.61 \mathrm{E}-10$ & $9.92 \mathrm{E}-08$ & $1.00 \mathrm{E}-09$ & 592 & 10 \\
\hline & 3 & $3.75 \mathrm{E}-08$ & $3.55 \mathrm{E}-08$ & $9.38 \mathrm{E}-08$ & $3.46 \mathrm{E}-08$ & $2.21 \mathrm{E}-06$ & $1.00 \mathrm{E}-07$ & 123 & 2 \\
\hline & 4 & $1.35 \mathrm{E}-09$ & $2.57 \mathrm{E}-09$ & $3.60 \mathrm{E}-09$ & $1.35 E-09$ & $9.99 E-08$ & $1.00 \mathrm{E}-08$ & 179 & 3 \\
\hline \multirow[t]{4}{*}{5} & 1 & $1.91 \mathrm{E}-05$ & $1.25 \mathrm{E}-05$ & $5.31 \mathrm{E}-05$ & $9.49 \mathrm{E}-07$ & 0.000127 & $1.00 \mathrm{E}-08$ & 14 & $<1$ \\
\hline & 2 & $1.40 \mathrm{E}-09$ & $8.66 \mathrm{E}-10$ & $8.81 \mathrm{E}-10$ & $1.40 \mathrm{E}-09$ & $9.98 \mathrm{E}-08$ & $1.00 \mathrm{E}-08$ & 309 & 5 \\
\hline & 3 & $2.81 \mathrm{E}-10$ & $2.75 \mathrm{E}-10$ & $1.43 \mathrm{E}-10$ & $2.81 \mathrm{E}-10$ & $9.94 \mathrm{E}-08$ & $1.00 \mathrm{E}-08$ & 311 & $5 \mathrm{~s}$ \\
\hline & 4 & $4.25 \mathrm{E}-09$ & $2.56 \mathrm{E}-09$ & $3.88 \mathrm{E}-10$ & $3.96 \mathrm{E}-09$ & $1.03 E-06$ & $1.00 \mathrm{E}-09$ & 225 & 3 \\
\hline \multirow[t]{4}{*}{6} & 1 & $8.71 \mathrm{E}-08$ & $8.26 \mathrm{E}-08$ & $3.05 E-07$ & $5.97 \mathrm{E}-08$ & $2.36 \mathrm{E}-05$ & $1.00 \mathrm{E}-08$ & 32 & $<1$ \\
\hline & 2 & $1.54 \mathrm{E}-09$ & $2.53 E-09$ & $1.23 \mathrm{E}-09$ & $1.54 \mathrm{E}-09$ & $9.93 \mathrm{E}-08$ & $1.00 \mathrm{E}-08$ & 290 & 5 \\
\hline & 3 & $2.46 \mathrm{E}-09$ & $4.56 \mathrm{E}-09$ & $3.14 \mathrm{E}-09$ & $2.46 \mathrm{E}-09$ & $9.96 \mathrm{E}-08$ & $1.00 \mathrm{E}-08$ & 462 & 9 \\
\hline & 4 & $1.17 \mathrm{E}-09$ & $1.18 \mathrm{E}-09$ & $9.23 \mathrm{E}-10$ & $1.17 \mathrm{E}-09$ & $9.91 \mathrm{E}-08$ & $1.00 \mathrm{E}-08$ & 195 & 3 \\
\hline
\end{tabular}

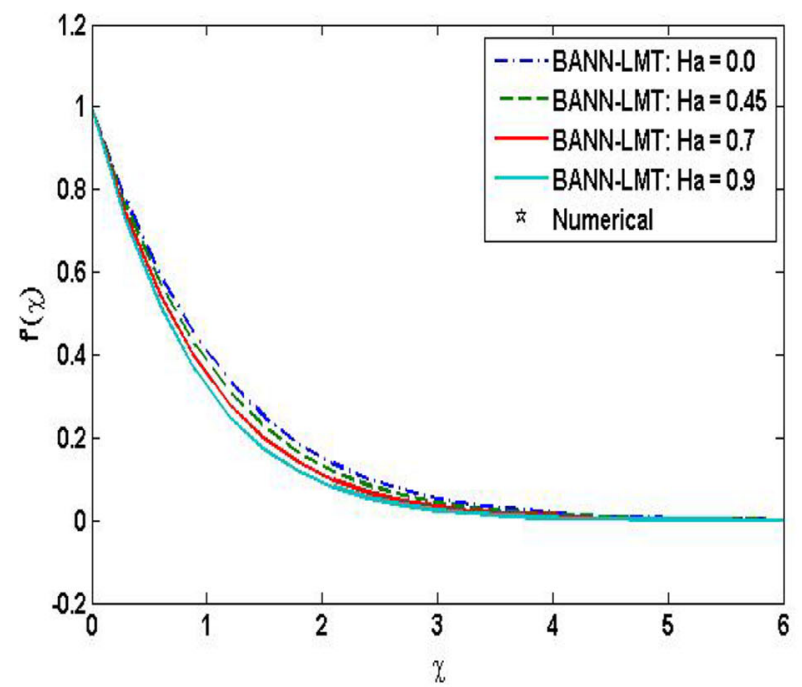

(a) Variation of $\mathrm{Ha}$ for $f^{\prime}$

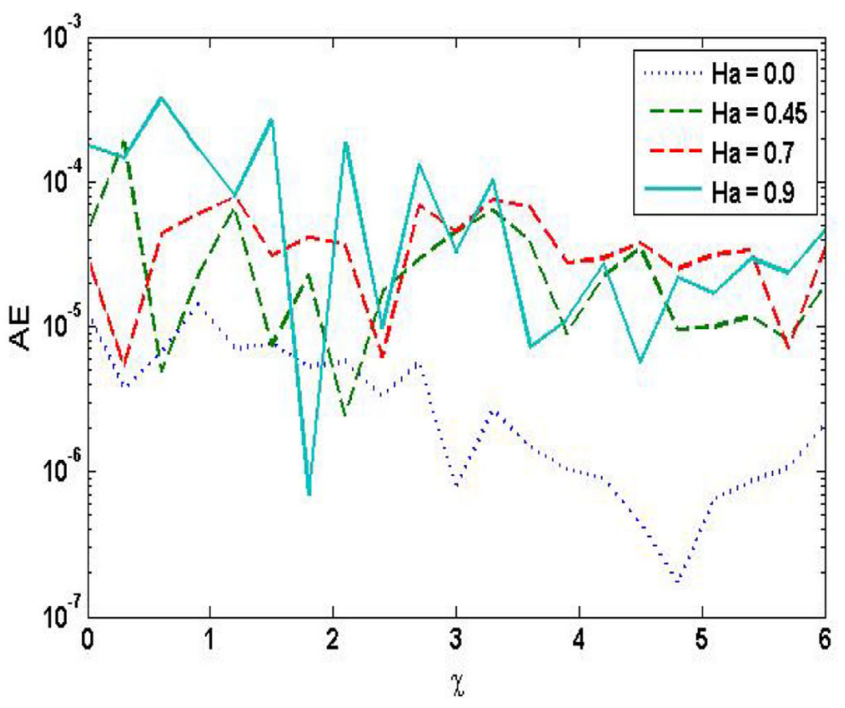

(b) $\mathrm{AE}$ analysis in variation of $\mathrm{Ha}$ for $f^{\prime}$

Fig. 7 Assessment of BANN-LMT for $f^{\prime}$ with reference dataset of MHD-TGNFM 


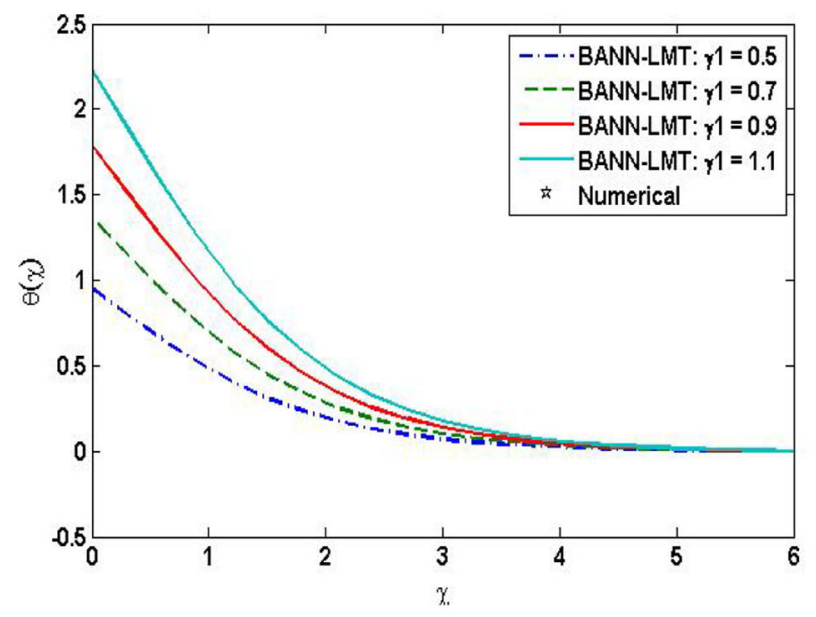

(a) Variation of $\gamma 1$ for $\theta$

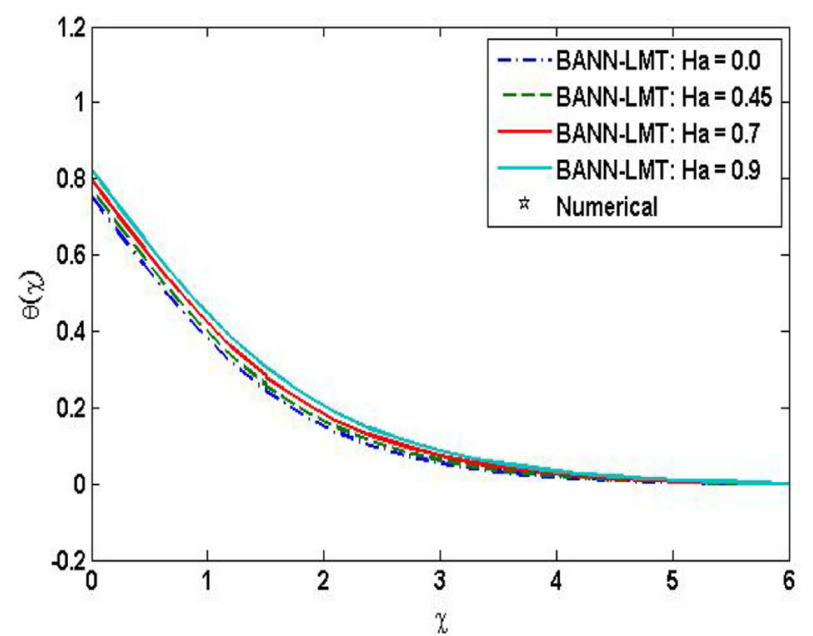

(c) Variation of $\mathrm{Ha}$ for $\theta$

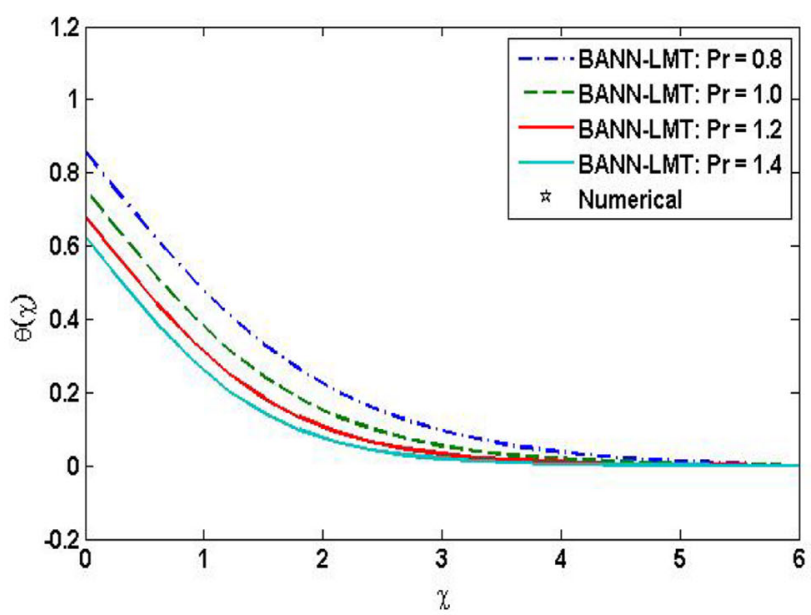

(e) Variation of $\operatorname{Pr}$ for $\theta$

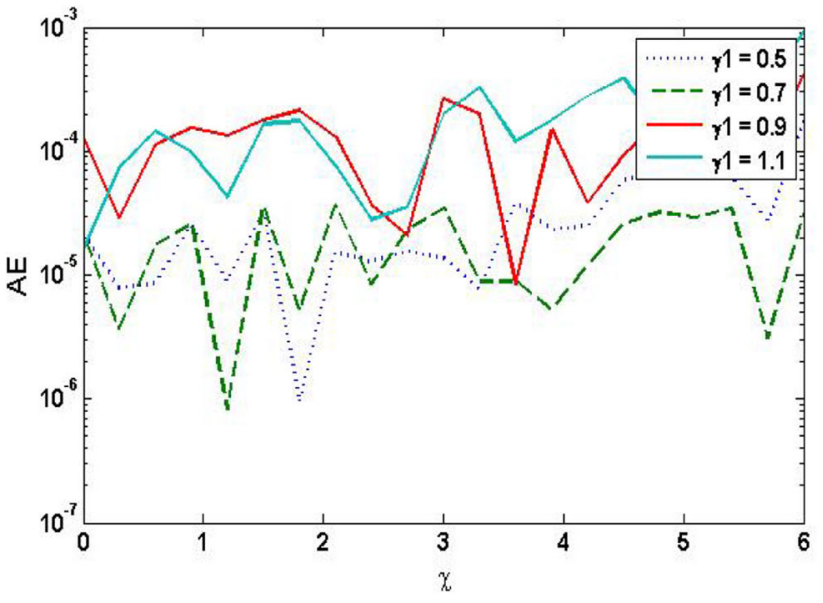

(b) AE analysis in variation of $\gamma 1$ for $\theta$

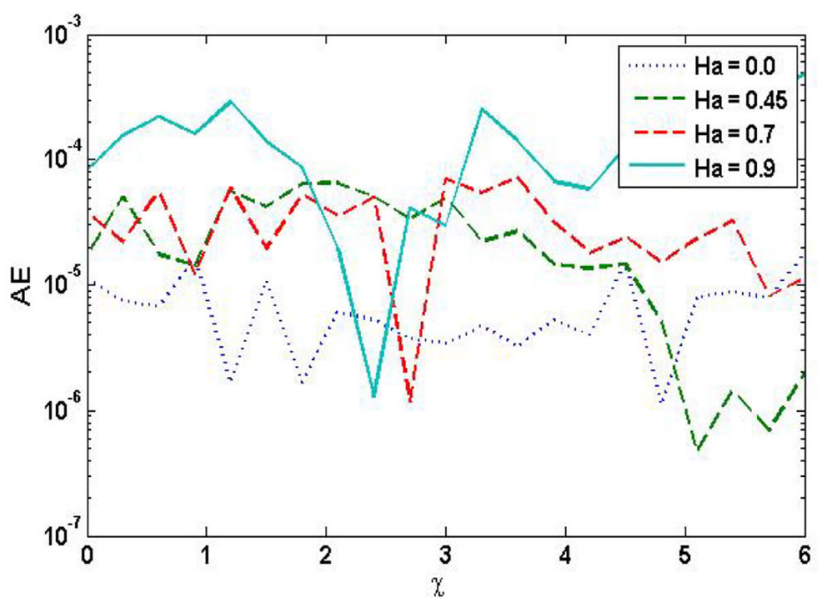

(d) $\mathrm{AE}$ analysis in variation of $\mathrm{Ha}$ for $\theta$

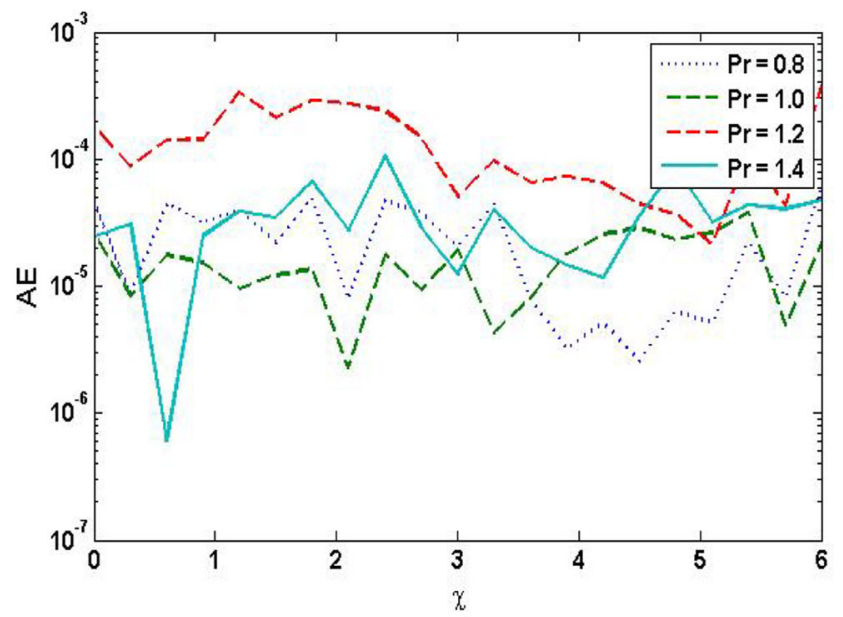

(f) $\mathrm{AE}$ analysis in variation of $\operatorname{Pr}$ for $\theta$

Fig. 8 Assessment of BANN-LMT for $\theta$ with reference dataset of MHD-TGNFM 


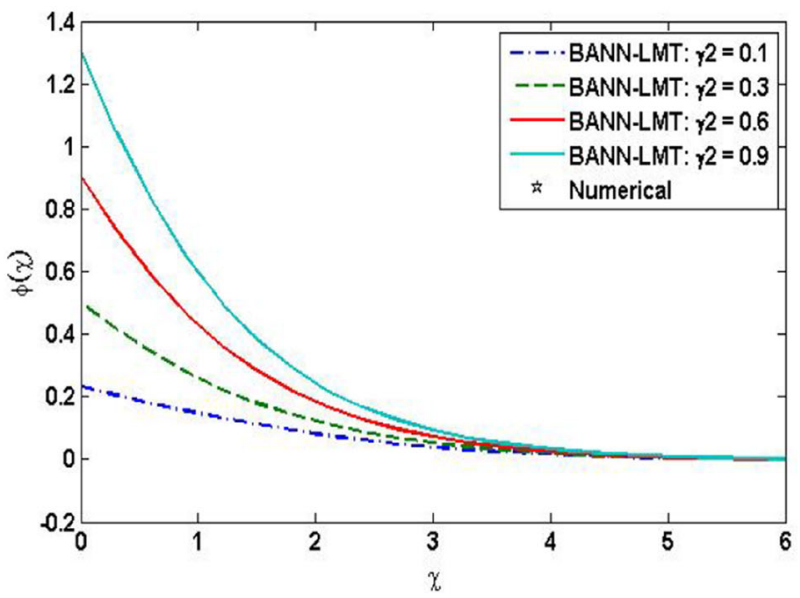

(a) Variation of $\gamma_{2}$ for $\varphi$

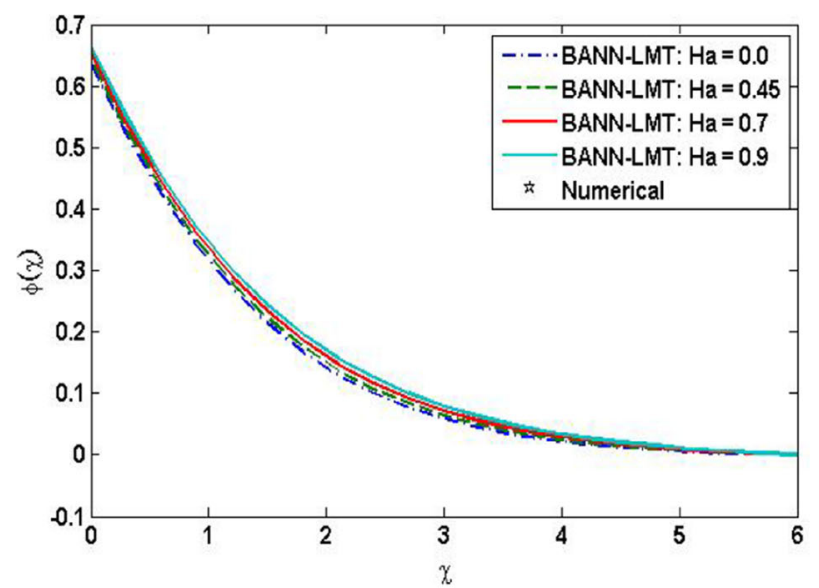

(c) Variation of $\mathrm{Ha}$ for $\varphi$

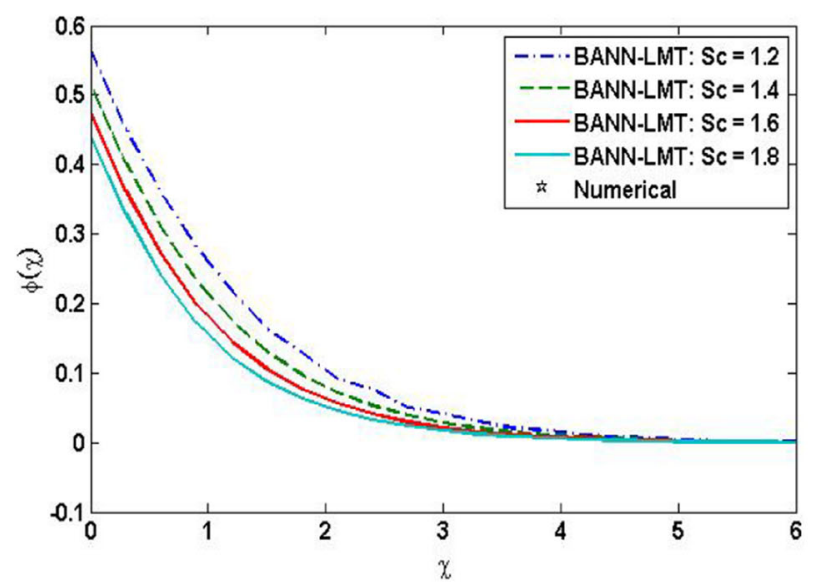

(e) Variation of $S c$ for $\varphi$

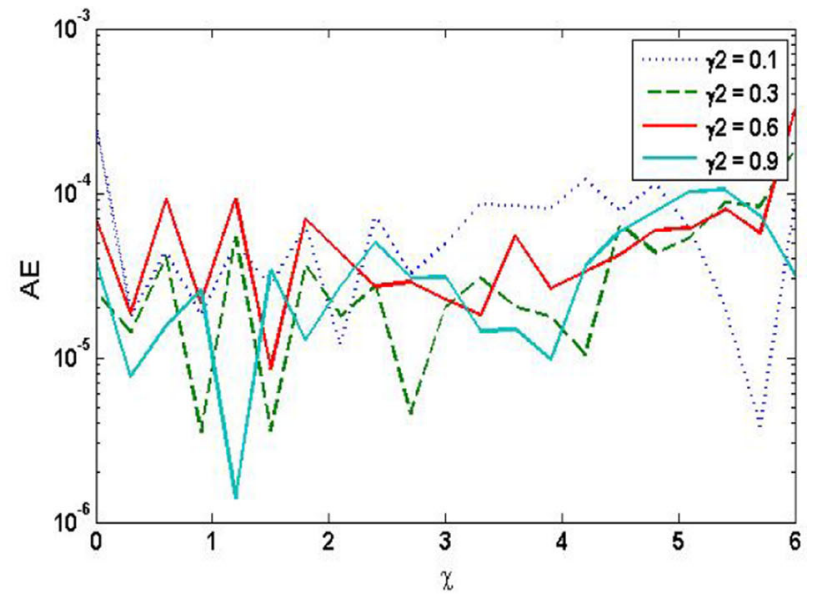

(b) AE analysis in variation of $\gamma_{2}$ for $\varphi$

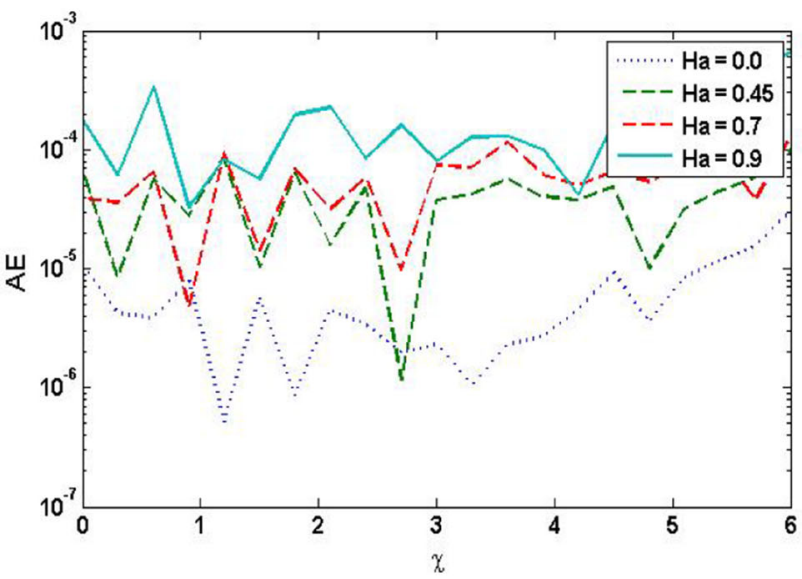

(d) $\mathrm{AE}$ analysis in variation of $\mathrm{Ha}$ for $\varphi$

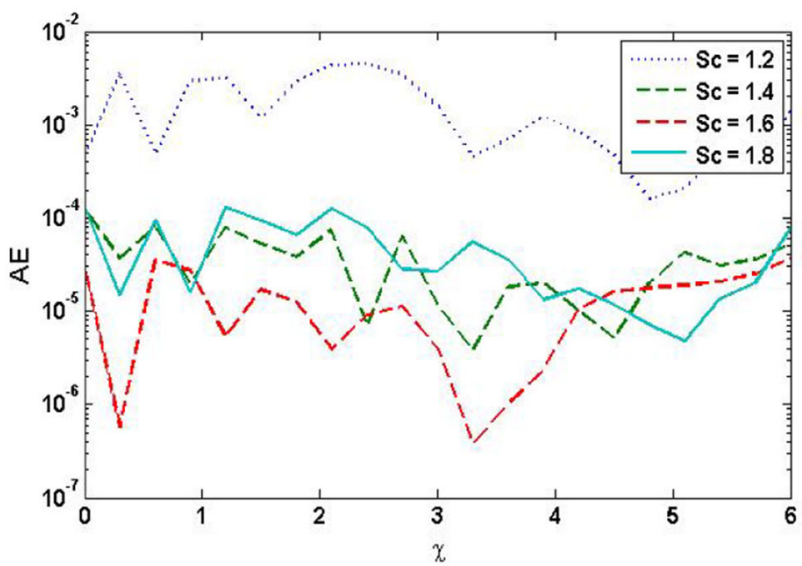

(f) $\mathrm{AE}$ analysis in variation of $S c$ for $\varphi$

Fig. 9 Assessment of BANN-LMT for $\varphi$ with reference dataset of MHD-TGNFM 


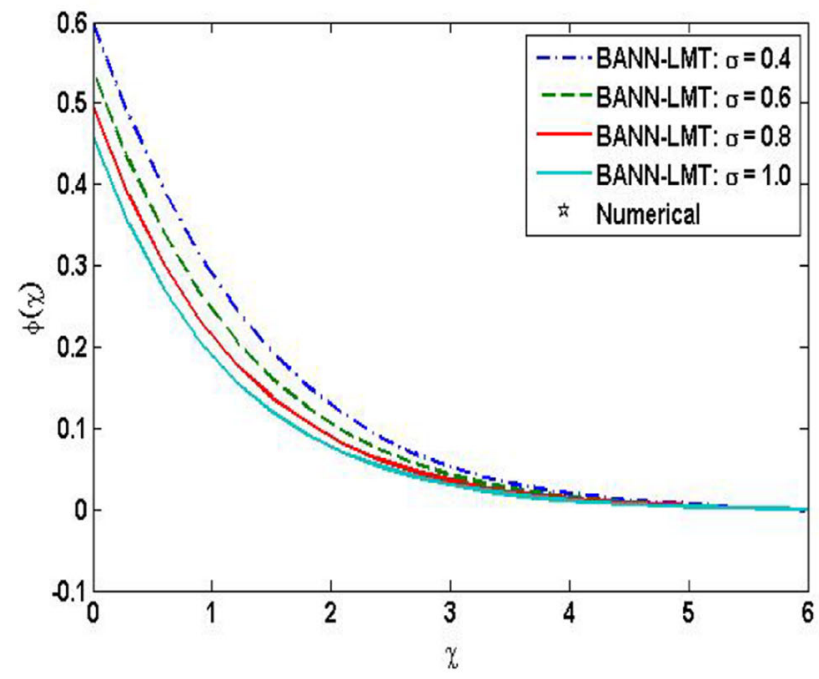

(g) Variation of $\sigma$ for $\varphi$

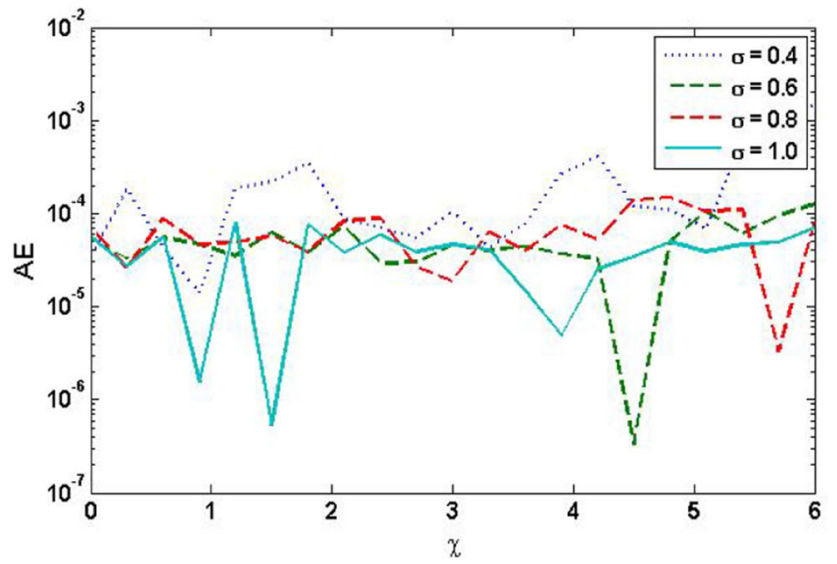

(h) $\mathrm{AE}$ analysis in variation of $\sigma$ for $\varphi$

Fig. 9 continued

error about $10^{-3}$ to $10^{-7}$. The temperature profile shows an increasing behavior when there is an increase in thermal Biot number and the local Hartmann number, whereas the increase in Prandtl number causes the decrease in temperature profile.

\subsection{Impact on Concentration Profile $\varphi(\chi)$}

MATLAB analyzed the results of BANN-LMT to determine the effect of variation of local Hartman number (Ha), local chemical reaction parameter $(\sigma)$, Schmidt number $(\mathrm{Sc})$, and concentration Biot number $\left(\gamma_{2}\right)$ on the concentration profile. Figure $9 \mathrm{a}, \mathrm{c}, \mathrm{e}$ and $\mathrm{g}$ shows the variation of concentration Biot number $\left(\gamma_{2}\right)$, local Hartman number (Ha), Schmidt number $(\mathrm{Sc})$ and local chemical reaction parameter $(\sigma)$ on the concentration profile. Figure $9 \mathrm{~b}, \mathrm{~d}, \mathrm{f}$ and $\mathrm{h}$ shows the absolute error about $10^{-3}$ to $10^{-6}, 10^{-3}$ to $10^{-7}, 10^{-2}$ to $10^{-7}$ and $10^{-2}$ to $10^{-7}$. The concentration profile rises with the upsurge in concentration Biot number and the local Hartmann number. And it drops with the rise in Schmidt number and the local chemical reaction parameter.

\section{Conclusion}

The analysis of BANN-LMT to determine the results of magnetohydrodynamic flow of third-grade nanofluid model (MHD-TGNFM) by varying the Prandtl number (Pr), local chemical reaction parameter $(\sigma)$, Schmidt number $(\mathrm{Sc})$, local Hartmann number $(\mathrm{Ha})$, thermal Biot number $\left(\gamma_{1}\right)$ and concentration Biot number $\left(\gamma_{2}\right)$. The PDEs of the third-grade nanofluid model are changed into a system of ODEs. Adam numerical solver generated the dataset of MHD-TGNFM. Eighty percentage of the reference data are used for the training, $10 \%$ for the testing and $10 \%$ for the validation of BANN-LMT. MSE plots, regression, performance and the other graphs justify the technique used for MHD-TGNFM. The temperature distribution rises with the increase in thermal Biot number and the local Hartmann number, whereas the increase in Prandtl number causes the reduction in temperature profile.

In the future research, the presented BANN-LMT can be used as an effective/accurate stochastic technique for secondgrade fluidic system [76], Casson nanofluid flow model [77], Jeffrey fluid model [78], dusty Casson fluid flow model [79], Darcy-Forchheimer flow model [80], MHD hybrid fluid flow model [81] and 2D Sutterby fluid flow model [82].

Funding None.

\section{Declarations}

Conflict of interest The authors declare that they have no competing interests.

\section{References}

1. Choi, S.U.; Eastman, J.A.: Enhancing Thermal Conductivity of Fluids with Nanoparticles (No. ANL/MSD/CP-84938; CONF951135-29). Argonne National Lab., IL, United States (1995)

2. Jang, S.P.; Choi, S.U.: Role of brownian motion in the enhanced thermal conductivity of nanofluids. Appl. Phys. Lett. 84(21), 4316-4318 (2004) 
3. Shukla, R.K.; Dhir, V.K.: Effect of Brownian motion on thermal conductivity of nano fluids. J. Heat Transf. 130, 042406 (2008)

4. Shukla, R.K.; Dhir, V.K.: Effect of Brownian motion on thermal conductivity of nanofluids. J. Heat Transf. 130(4) (2008)

5. Bhatti, M.M.; Michaelides, E.E.: Study of Arrhenius activation energy on the thermo-bioconvection nanofluid flow over a Riga plate. J. Therm. Anal. Calorim. 1-10 (2020)

6. Souayeh, B.; Kumar, K.G.; Reddy, M.G.; Rani, S.; Hdhiri, N.; Alfannakh, H.; Rahimi-Gorji, M.: Slip flow and radiative heat transfer behavior of Titanium alloy and ferromagnetic nanoparticles along with suspension of dusty fluid. J. Mol. Liq. 290, 111223 (2019)

7. Makinde, O.D.; Mabood, F.; Khan, W.A.; Tshehla, M.S.: MHD flow of a variable viscosity nanofluid over a radially stretching convective surface with radiative heat. J. Mol. Liq. 219, 624-630 (2016)

8. Sheremet, M.A.; Pop, I.; Rosca, N.C.: Magnetic field effect on unsteady natural convection in a wavy-walled cavity filled with a nanofluid: buongiorno's mathematical model. J. Taiwan Inst. Chem. Eng. 61, 211-222 (2016)

9. Makinde, O.D.; Aziz, A.: Boundary layer flow of a nanofluid past a stretching sheet with a convective boundary condition. Int. J. Therm. Sci. 50(7), 1326-1332 (2011)

10. Buongiorno, J.: Convective transport in nanofluids (2006)

11. Ghahremanian, S.; Abbassi, A.; Mansoori, Z.; Toghraie, D.: Investigation the nanofluid flow through a nanochannel to study the effect of nanoparticles on the condensation phenomena. J. Mol. Liq. 311, $113310(2020)$

12. Ahmad, S.; Khan, M.I.; Hayat, T.; Alsaedi, A.: Inspection of Coriolis and Lorentz forces in nanomaterial flow of non-Newtonian fluid with activation energy. Phys. A Stat. Mech. Appl. 540, 123057 (2020)

13. Awad, F.G.; Sibanda, P.; Khidir, A.A.: Thermodiffusion effects on magneto-nanofluid flow over a stretching sheet. Bound. Value Probl. 2013(1), 1-13 (2013)

14. Reddy, M.G.: Influence of thermal radiation, viscous dissipation and hall current on MHD convection flow over a stretched vertical flat plate. Ain Shams Eng. J. 5(1), 169-175 (2014)

15. Reddy, M.G.: Thermal radiation and chemical reaction effects on MHD mixed convective boundary layer slip flow in a porous medium with heat source and Ohmic heating. Eur. Phys. J. Plus 129(3), 1-17 (2014)

16. Jonnadula, M.; Polarapu, P.; Reddy, G.: Influence of thermal radiation and chemical reaction on MHD flow, heat and mass transfer over a stretching surface. Procedia Eng. 127, 1315-1322 (2015)

17. Ramzan, M.; Gul, H.; Kadry, S.; Chu, Y.M.: Role of bioconvection in a three dimensional tangent hyperbolic partially ionized magnetized nanofluid flow with Cattaneo-Christov heat flux and activation energy. Int. Commun. Heat Mass Transf. 120, 104994 (2021)

18. Mahanthesh, B.; Shehzad, S.A.; Ambreen, T.; Khan, S.U.: Significance of Joule heating and viscous heating on heat transport of MoS2-Ag hybrid nanofluid past an isothermal wedge. J. Therm. Anal. Calorim. 143(2) (2021)

19. Shashikumar, N.S.; Gireesha, B.J.; Mahanthesh, B.; Prasannakumara, B.C.: Brinkman-Forchheimer flow of SWCNT and MWCNT magneto-nanoliquids in a microchannel with multiple slips and Joule heating aspects. Multidiscip. Model. Mater. Struct. (2018)

20. Mackolil, J.; Mahanthesh, B.: Exact and statistical computations of radiated flow of nano and Casson fluids under heat and mass flux conditions. Journal of Computational Design and Engineering 6(4), 593-605 (2019)

21. Mahanthesh, B.; Joseph, T.V.: Dynamics of magneto-nano thirdgrade fluid with Brownian motion and thermophoresis effects in the pressure type die. J Nanofluids 8(4), 870-875 (2019)
22. Mackolil, J.; Mahanthesh, B.: Sensitivity analysis of Marangoni convection in $\mathrm{TiO} 2-\mathrm{EG}$ nanoliquid with nanoparticle aggregation and temperature-dependent surface tension. J. Therm. Anal. Calorim. 143(3), 2085-2098 (2021)

23. Mahanthesh, B.; Gireesha, B.J.; Gorla, R.S.R.: Nanoparticles effect on 3D flow, heat and mass transfer of nanofluid with nonlinear radiation, thermal-diffusion and diffusion-thermo effects. J. Nanofluids 5(5), 669-678 (2016)

24. Lade, R.; Wasewar, K.; Sangtyani, R.; Kumar, A.; Peshwe, D.; Shende, D.: Effect of aluminium nanoparticles on rheology of AP based comsposite propellant: experimental study and mathematical modelling. Molecular Simulation 1-10 (2021)

25. Mahanthesh, B.; Gireesha, B.J.; Shehzad, S.A.; Ibrar, N.; Thriveni, $\mathrm{K}$.: Analysis of a magnetic field and Hall effects in nanoliquid flow under insertion of dust particles. Heat Transf. 49(3), 1632-1648 (2020)

26. Mahanthesh, B.: Statistical and exact analysis of MHD flow due to hybrid nanoparticles suspended in $\mathrm{C} 2 \mathrm{H} 6 \mathrm{O} 2-\mathrm{H} 2 \mathrm{O}$ hybrid base fluid. In: Mathematical methods in engineering and applied sciences, pp. 185-228. CRC Press, Florida (2020)

27. Mahanthesh, B.; Shashikumar, N.S.; Lorenzini, G.: Heat transfer enhancement due to nanoparticles, magnetic field, thermal and exponential space-dependent heat source aspects in nanoliquid flow past a stretchable spinning disk. J. Therm. Anal. Calorim. 1-9 (2020)

28. Thriveni, K.; Mahanthesh, B.: Optimization and sensitivity analysis of heat transport of hybrid nanoliquid in an annulus with quadratic Boussinesq approximation and quadratic thermal radiation. Eur. Phys. J. Plus 135(6), 1-22 (2020)

29. Abdel-Rahman, G.M.: Unsteady magnetohydrodynamic flow of a non-newtonian nanofluid with thermal radiation effects in nondarcian porous medium over stretching surface. J. Nanofluids 5(5), 721-727 (2016)

30. Hussanan, A.; Ismail, Z.; Khan, I.; Hussein, A.G.; Shafie, S.: Unsteady boundary layer MHD free convection flow in a porous medium with constant mass diffusion and Newtonian heating. Eur. Phys. J. Plus 129(3), 1-16 (2014)

31. Mustafa, M.; Khan, J.A.; Hayat, T.; Alsaedi, A.: Buoyancy effects on the MHD nanofluid flow past a vertical surface with chemical reaction and activation energy. Int. J. Heat Mass Transf. 108, 1340-1346 (2017)

32. Khanafer, K.; Vafai, K.: A critical synthesis of thermophysical characteristics of nanofluids. Int. J. Heat Mass Transf. 54(19-20), 4410-4428 (2011)

33. Hamad, M.A.A.; Pop, I.: Scaling transformations for boundary layer flow near the stagnation-point on a heated permeable stretching surface in a porous medium saturated with a nanofluid and heat generation/absorption effects. Transp. Porous Media 87(1), 25-39 (2011)

34. Pal, D.; Mandal, G.: Mixed convection-radiation on stagnationpoint flow of nanofluids over a stretching/shrinking sheet in a porous medium with heat generation and viscous dissipation. J. Petrol. Sci. Eng. 126, 16-25 (2015)

35. Mushtaq, A.; Mustafa, M.; Hayat, T.; Alsaedi, A.: Numerical study for rotating flow of nanofluids caused by an exponentially stretching sheet. Adv. Powder Technol. 27(5), 2223-2231 (2016)

36. Magyari, E.; Keller, B.: Heat and mass transfer in the boundary layers on an exponentially stretching continuous surface. J. Phys. D Appl. Phys. 32(5), 577 (1999)

37. Cortell, R.: Viscous flow and heat transfer over a nonlinearly stretching sheet. Appl. Math. Comput. 184(2), 864-873 (2007)

38. Seth, G.S.; Mishra, M.K.: Analysis of transient flow of MHD nanofluid past a non-linear stretching sheet considering Navier's slip boundary condition. Adv. Powder Technol. 28(2), 375-384 (2017) 
39. Jamshed, W.; Eid, M.R.; Nasir, N.A.A.M.; Nisar, K.S.; Aziz, A.; Shahzad, F.; Saleel, C.A.; Shukla, A.: Thermal examination of renewable solar energy in parabolic trough solar collector utilizing Maxwell nanofluid: a noble case study. Case Stud Therm. Eng. 27, 101258 (2021)

40. Al-Hossainy, A.F.; Eid, M.R.: Combined theoretical and experimental DFT-TDDFT and thermal characteristics of 3-D flow in rotating tube of [PEG+ $\mathrm{H} 2 \mathrm{O} / \mathrm{SiO} 2-\mathrm{Fe} 3 \mathrm{O} 4] \mathrm{C}$ hybrid nanofluid to enhancing oil extraction. Waves Random Complex Media 1-26 (2021)

41. Jamshed, W.; Nisar, K.S.; Ibrahim, R.W.; Shahzad, F.; Eid, M.R.: Thermal expansion optimization in solar aircraft using tangent hyperbolic hybrid nanofluid: a solar thermal application. J. Market. Res. 14, 985-1006 (2021)

42. Sajid, T.; Jamshed, W.; Shahzad, F.; Eid, M.R.; Alshehri, H.M.; Goodarzi, M.; Akgül, E.K.; Nisar, K.S.: Micropolar fluid past a convectively heated surface embedded with nth order chemical reaction and heat source/sink. Phys. Scr. 96(10), 104010 (2021)

43. Sajid, T.; Jamshed, W.; Shahzad, F.; El Boukili, A.; Ez-Zahraouy, H.; Nisar, K.S.; Eid, M.R.: Study on heat transfer aspects of solar aircraft wings for the case of Reiner-Philippoff hybrid nanofluid past a parabolic trough: Keller box method. Phys. Scr. (2021)

44. Shahzad, F.; Jamshed, W.; Sajid, T.; Nisar, K.S.; Eid, M.R.: Heat transfer analysis of MHD rotating flow of $\mathrm{Fe} 3 \mathrm{O} 4$ nanoparticles through a stretchable surface. Commun. Theor. Phys. 73(7), 075004 (2021)

45. Nazeer, M.; Khan, M.I.; Chu, Y.M.; Kadry, S.; Eid, M.R.: Mathematical modeling of multiphase flows of third-grade fluid with lubrication effects through an inclined channel: analytical treatment. J. Dispers. Sci. Technol. 1-13 (2021)

46. Shamshuddin, M.D. and Eid, M.R., 2021. $\mathrm{n}$ th order reactive nanoliquid through convective elongated sheet under mixed convection flow with joule heating effects. Journal of Thermal Analysis and Calorimetry, pp.1-15.

47. Sajid, M.: Application of parameter differentiation for flow of a third grade fluid past an infinite porous plate. Numer. Methods Partial Differ. Equ. Int. J. 26(1), 221-228 (2010)

48. Rajagopal, K.R.; Szeri, A.Z.; Troy, W.: An existence theorem for the flow of a non-Newtonian fluid past an infinite porous plate. Int. J. Non-Linear Mech. 21(4), 279-289 (1986)

49. Cortell, R.: Numerical solutions for the flow of a fluid of grade three past an infinite porous plate. Int. J. Non-Linear Mech. 28(6), 623-626 (1993)

50. Mekheimer, K.S.; Hasona, W.M.; Abo-Elkhair, R.E.; Zaher, A.Z.: Peristaltic blood flow with gold nanoparticles as a third grade nanofluid in catheter: Application of cancer therapy. Phys. Lett. A 382(2-3), 85-93 (2018)

51. Hatami, M.; Hatami, J.; Ganji, D.D.: Computer simulation of MHD blood conveying gold nanoparticles as a third grade non-Newtonian nanofluid in a hollow porous vessel. Comput. Methods Programs Biomed. 113(2), 632-641 (2014)

52. Hamzehnezhad, A.; Fakour, M.; Ganji, D.D.; Rahbari, A.: Heat transfer and fluid flow of blood flow containing nanoparticles through porous blood vessels with magnetic field. Math. Biosci 283, 38-47 (2017)

53. Xu, A.; Chang, H.; Xu, Y.; Li, R.; Li, X.; Zhao, Y.: Applying artificial neural networks (ANNs) to solve solid waste-related issues: a critical review. Waste Manage. 124, 385-402 (2021)

54. Mangini, S.; Tacchino, F.; Gerace, D.; Bajoni, D.; Macchiavello, C.: Quantum computing models for artificial neural networks. EPL (Europhysics Letters) 134(1), 10002 (2021)

55. Zafar, S.; Nazir, M.; Sabah, A.; Jurcut, A.D.: Securing bio-cyber interface for the internet of bio-nano things using particle swarm optimization and artificial neural networks based parameter profiling. Comput. Biol. Med. 136, 104707 (2021)
56. Withington, L.; de Vera, D.D.P.; Guest, C.; Mancini, C.; Piwek, P.: Artificial neural networks for classifying the time series sensor data generated by medical detection dogs. Expert Syst. Appl. 184, 115564 (2021)

57. Santoni, M.; Piva, F.; Porta, C.; Bracarda, S.; Heng, D.Y.; Matrana, M.R.; Grande, E.; Mollica, V.; Aurilio, G.; Rizzo, M.; Giulietti, M.: Artificial neural networks as a way to predict future kidney cancer incidence in the United States. Clin. Genitourin. Cancer 19(2), e84-e91 (2021)

58. Sermesant, M.; Delingette, H.; Cochet, H.; Jaïs, P.; Ayache, N.: Applications of artificial intelligence in cardiovascular imaging. Nat. Rev. Cardiol. 1-10 (2021)

59. Shoaib, M.; Raja, M.A.Z.; Farhat, I.; Shah, Z.; Kumam, P.; Islam, S.: Soft computing paradigm for Ferrofluid by exponentially stretched surface in the presence of magnetic dipole and heat transfer. Alex. Eng. J. (2021)

60. Almalki, M.M.; Alaidarous, E.S.; Maturi, D.; Raja, M.A.Z.; Shoaib, M.: A Levenberg-marquardt backpropagation neural network for the numerical treatment of squeezing flow with heat transfer model. IEEE Access. 6, 227340-227348 (2020)

61. Shoaib, M.; et al.: Neuro-computing networks for entropy generation under the influence of MHD and thermal radiation. Surf. Interfaces 101243 (2021)

62. Sabir, Z.; et al.: Design of stochastic numerical solver for the solution of singular three-point second-order boundary value problems. Neural Comput. Appl. 1-17 (2020)

63. Ahmad, I., et al.: Novel applications of intelligent computing paradigms for the analysis of nonlinear reactive transport model of the fluid in soft tissues and microvessels. Neural Comput. Appl. 31(12), 9041-9059 (2019)

64. Ahmad, I.; et al.: Integrated neuro-evolution-based computing solver for dynamics of nonlinear corneal shape model numerically. Neural Comput. Appl. 1-17 (2020)

65. Shoaib, M., et al.: A stochastic numerical analysis based on hybrid NAR-RBFs networks nonlinear SITR model for novel COVID19 dynamics. Comput. Methods Programs Biomed. 202, 105973 (2021)

66. Miller, B.L.: A queueing reward system with several customer classes. Manag. Sci. 16(3), 234-245 (1969)

67. Joseph, D.D.; Renardy, M.; Saut, J.C.: Hyperbolicity and change of type in the flow of viscoelastic fluids. Arch. Ration. Mech. Anal. 87(3), 213-251 (1985)

68. Hayat, T.; Riaz, R.; Aziz, A.; Alsaedi, A.: Influence of Arrhenius activation energy in MHD flow of third grade nanofluid over a nonlinear stretching surface with convective heat and mass conditions. Phys. A Stat. Mech. Appl. 549, 124006 (2020)

69. Chen, J.; Li, K.; Zhang, Z.; Li, K; Yu, P.S.: A survey on applications of artificial intelligence in fighting against covid-19. arXiv preprint http://arxiv.org/abs/2007.02202 (2020)

70. Ramesh, A.N.; Kambhampati, C.; Monson, J.R.; Drew, P.J.: Artificial intelligence in medicine. Ann. R. Coll. Surg. Engl. 86(5), 334 (2004)

71. Chen, J.; Remulla, D.; Nguyen, J.H.; Liu, Y.; Dasgupta, P.; Hung, A.J.: Current status of artificial intelligence applications in urology and their potential to influence clinical practice. BJU Int. 124(4), 567-577 (2019)

72. Sabir, Z., et al.: Design of neuro-swarming-based heuristics to solve the third-order nonlinear multi-singular Emden-Fowler equation. Eur. Phys. J. Plus 135(6), 410 (2020)

73. Jadoon, I., et al.: Design of evolutionary optimized finite difference based numerical computing for dust density model of nonlinear Van-der Pol Mathieu's oscillatory systems. Math. Comput. Simul. 181, 444-470 (2020)

74. Rakha, E.A.; Toss, M.; Shiino, S.; Gamble, P.; Jaroensri, R.; Mermel, C.H.; Chen, P.H.C.: Current and future applications of artificial 
intelligence in pathology: a clinical perspective. J. Clin. Pathol. 74(7), 409-414 (2021)

75. Shan, T.; Tay, F.R.; Gu, L.: Application of artificial intelligence in dentistry. J. Dent. Res. 100(3), 232-244 (2021)

76. Shoaib, M.; Raja, M.A.Z.; Jamshed, W.; Nisar, K.S.; Khan, I.; Farhat, I.: Intelligent computing Levenberg Marquardt approach for entropy optimized single-phase comparative study of second grade nanofluidic system. Int. Commun. Heat Mass Transf. 127, 105544 (2021)

77. Umar, M., et al.: The 3-D flow of Casson nanofluid over a stretched sheet with chemical reactions, velocity slip, thermal radiation and Brownian motion. Therm. Sci. 24(5A), 2929 (2020)

78. Shoaib, M., et al.: The effect of slip condition on the threedimensional flow of Jeffrey fluid along a plane wall with periodic suction. J. Braz. Soc. Mech. Sci. Eng. 39(7), 2495-2503 (2017)
79. Siddiqa, S., et al.: Radiative heat transfer analysis of nonNewtonian dusty Casson fluid flow along a complex wavy surface. Numerical Heat Transfer, Part A: Applications 73(4), 209-221 (2018)

80. Uddin, I.; R. Akhtar, et al.: Numerical treatment for darcyforchheimer flow of sisko nanomaterial with nonlinear thermal radiation by lobatto IIIA technique. Math. Probl. Eng. 2019 (2019)

81. Shoaib, M., et al.: Numerical investigation for rotating flow of MHD hybrid nanofluid with thermal radiation over a stretching sheet. Sci. Rep. 10(1), 1-15 (2020)

82. Sabir, Z., et al.: A numerical approach for two-dimensional Sutterby fluid flow bounded at a stagnation point with an inclined magnetic field and thermal radiation impacts. Therm. Sci. 00, $186-186$ (2020) 